\title{
The Role of Defendant Race and Racially Charged Media in the Canadian Courtroom
}

\author{
by
}

Laura McManus

\begin{abstract}
A thesis submitted to the Faculty of Graduate and Postdoctoral Affairs in partial fulfillment of the requirements for the degree of

Master of Arts

in

Psychology
\end{abstract}

Carleton University

Ottawa, Ontario

(C) 2014 Laura McManus 


\begin{abstract}
This study sought to examine the influence of defendant race and racially charged media on Canadian mock jurors' trial decisions. Two-hundred and ten participants read a racially charged or racially neutral article followed by a trial transcript involving a White, Black, or Aboriginal-Canadian defendant. Diverging from previous findings, this study did not find an effect of defendant race or race salience on verdict judgements or causal attributions. Rather, it demonstrated that when race is not a central feature to the case, making race salient may actually increase levels of racial bias for some mock jurors. The implication of this research largely appears to be that race salience affects Canadian and American mock jurors differently. Potential explanations and further implications for these unexpected findings are discussed.
\end{abstract}




\section{Acknowledgements}

I would like to extend my thanks and appreciation to all those who have helped me over the past two years. First and foremost, I would like to offer my sincerest gratitude to my supervisor and mentor, Dr. Evelyn Maeder for her continuous support and thoughtful encouragement. I attribute my successes to her indispensable knowledge, devotement, and patience throughout this process.

I also have had the fortune of being surrounded by great family, friends, and lab mates. Thank you to my parents and brother, whose love and encouragement throughout my studies has made this accomplishment possible. To Chris McLean, who stood by me during my nights of endless typing to offer emotional support and a good laugh when it was needed. And finally, I would like to thank Susan Yamamoto for her endless positivity and moral support which she provided at every stage. 


\section{Table of Contents}

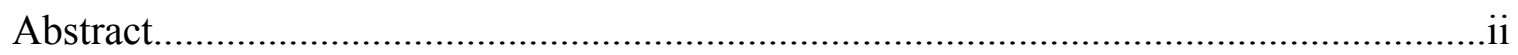

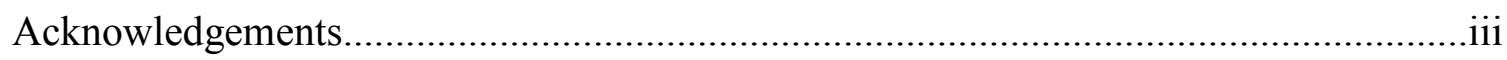

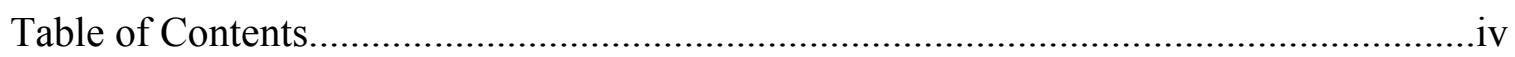

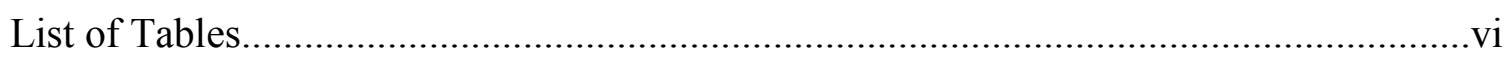

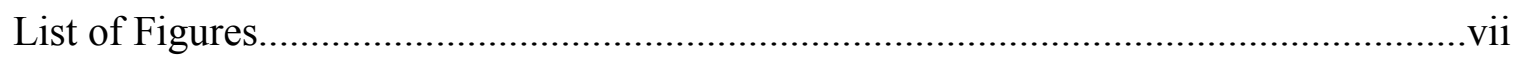

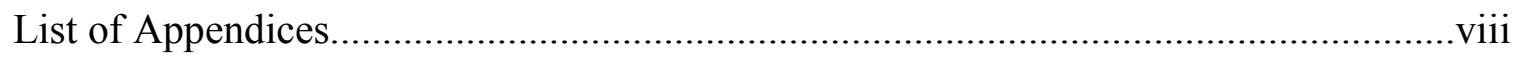

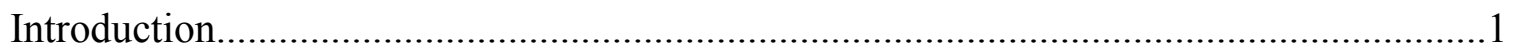

- Juror Decision-Making.........................................................................4

- $\quad$ Race and Legal Judgements............................................................

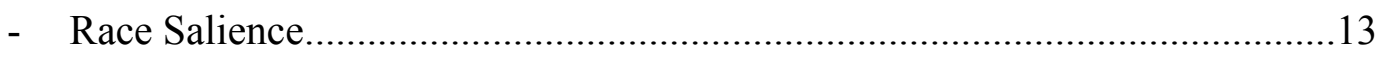

- Racially Charged Media...................................................................... 19

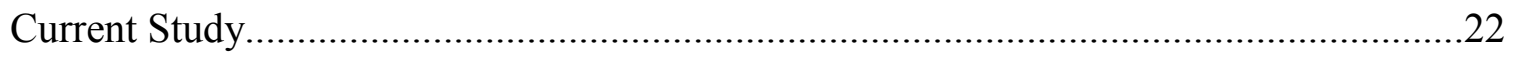

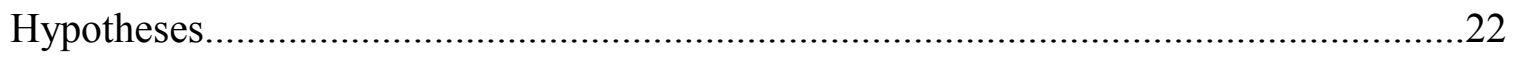

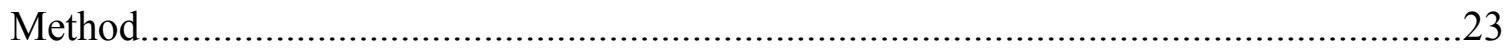

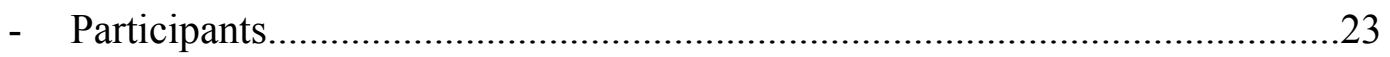

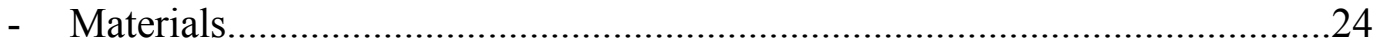

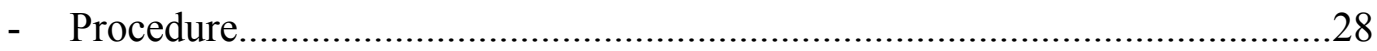

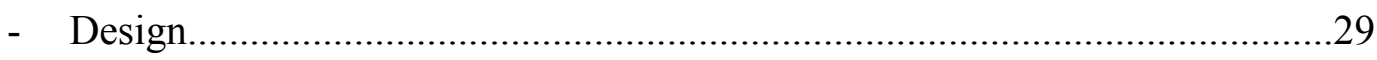




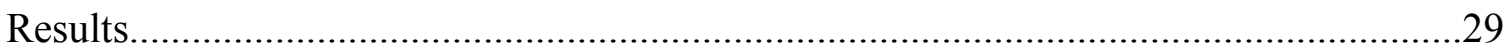

- Negative Racial Stereotypes and Jurors' Trial Decisions................................30

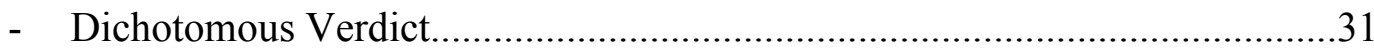

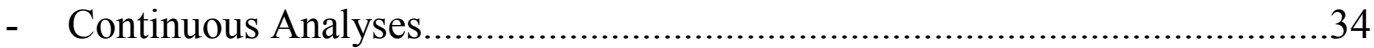

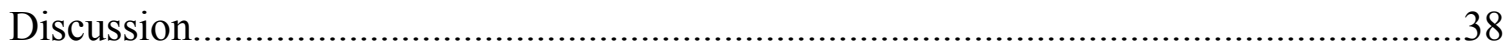

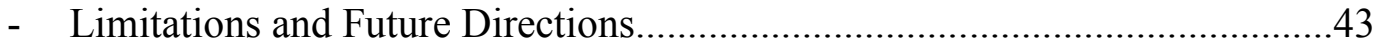

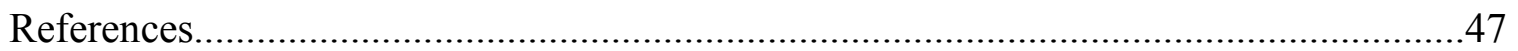




\section{List of Tables}

Table 1. Relationships between Negative Personal Stereotypes and Trial Decisions

by Defendant Race........................................................................ 31

Table 2. Summary of Logistic Regression Analysis from the DOM Charge

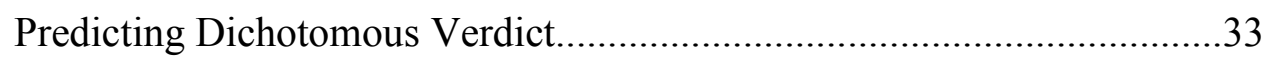

Table 3. Summary of Logistic Regression Analysis from the Impaired Driving

Charge Predicting Dichotomous Verdict...............................................34

Table 4. Descriptive Statistics by Defendant Race...............................................

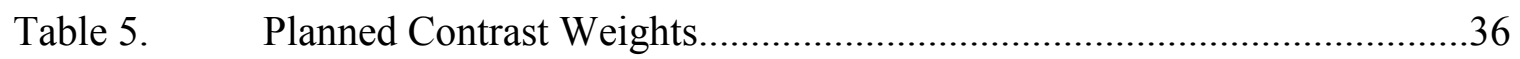




\section{List of Figures}

Figure 1. Effect of article type on racialized defendants' sentence length for the

DOM charge

Figure 2. Effect of article specificity on racialized defendants's sentence length for

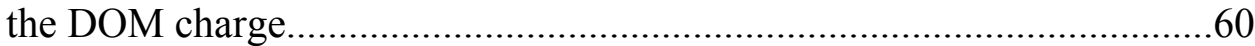




\section{List of Appendices}

Appendix A. News Article: Race Specific..................................................................61

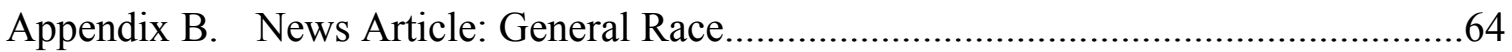

Appendix C. News Article: Race Neutral...............................................................67

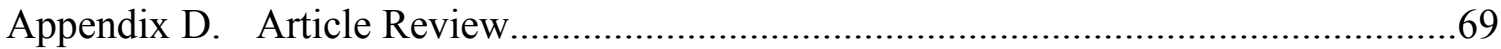

Appendix E. Trial Transcript................................................................................

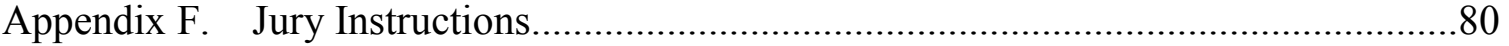

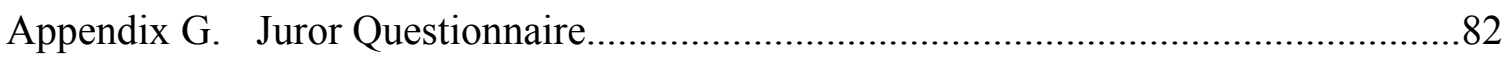

Appendix H. Informed Consent............................................................................90

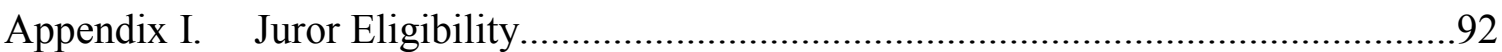

Appendix J. Debriefing Form................................................................................93

Appendix K . Study Consent-to-keep-data Form..........................................................95 
The Role of Defendant Race and Racially Charged Media in the Canadian Courtroom As a continuously evolving multicultural society, Canada presents itself as colourblind (Canadian Multiculturalism, 2012). However, not all Canadian institutions reflect Canada's increasingly diverse and pluralistic society. Within the Canadian Criminal Justice System, minorities are vastly overrepresented, calling into question whether minority defendants receive equal and impartial treatment within the courts (Statistics Canada, 2008).

The potential for racial bias in trials involving minority defendants has been recognized by the Canadian courts. In R. v. Parks (1993), the court ruled that the accused should be permitted to ask prospective jurors whether their ability to judge impartially would be affected by the race of the defendant in circumstances where there is a heightened possibility of racial prejudice. Subsequently, in R. v. Williams (1998), the court acknowledged the diversity of racial bias, and put forth the possibility that some prospective jurors might have negative attitudes towards not only Black-Canadians, but Aboriginal-Canadians as well.

Despite improvements in this area, racial discrimination continues to be a concern of great social importance in Canada. Over the past decade, Black and Aboriginal incarcerated individuals have accounted for the fastest growing sub-groups in Canadian corrections. While the overall inmate population has modestly increased by $2.4 \%$, the Black inmate population has increased significantly by over $40 \%$ in the last 10 years (Office of the Correctional Investigator, 2013). Black individuals now account for 9\% of the inmate population, far exceeding their representation in Canadian society (which is 2.5\%; Statistics Canada, 2008). Similarly, Aboriginal-Canadians make up roughly 4\% of 
the Canadian population, while accounting for $23.2 \%$ of the federally incarcerated population (Office of the Correctional Investigator, 2013).

Many factors have been put forth as contributing to the disproportionate number of minorities in corrections. Sampson and Lauritsen (1997) suggest that racial differences in criminal offending patterns are the primary cause of overrepresentation. In general, Black offenders are more likely to be charged with serious offences such as acts intended to cause injury, illicit drugs, and theft compared to the general population (Sampson \& Lauritsen, 1997). Similarly, some argue that many Aboriginal-Canadians in corrections are persistent offenders with violent offence backgrounds, increasing their likelihood of incarceration (Yassine \& Bonta, 2009). Various other studies, however, advocate that the overrepresentation of minorities in corrections is a direct result of differential treatment. Research suggests that Black individuals are up to three times more likely to be arrested than White individuals, even after controlling for legal variables such as prior criminal history and type of offence (Huizinga, Thornberry, Knight, \& Lovegrove, 2007). This disparity appears to increase when charges that carry a minimum sentence are taken into account (Rehavi \& Starr, 2012). A similar pattern can be seen with Aboriginal-Canadian defendants. Studies have consistently reported that the risk of imprisonment is much higher for Aboriginal-Canadian defendants relative to other races (Snowball \& Weaterburn, 2007; Stefensmeier, Ulmar, \& Kramer, 1998). The Aboriginal Justice Inquiry (1999) found that on average, Aboriginal-Canadians face 25\% more charges than non-Aboriginal offenders, with $22 \%$ facing four charges or more. Furthermore, across all provinces, Aboriginal offenders are disproportionally admitted to custody with indeterminate or life sentences (Public Safety Canada, 2012). 
In response to the over-representation of Aboriginal-Canadians in corrections, Canadian legislation has opted to incorporate principles of restorative justice into Canadian Criminal law. In 1996, Bill C-41 was enacted to provide courts with clear sentencing guidelines, with some of the provisions concerned specifically with the overincarceration of Aboriginal offenders. The Bill resulted in the creation of section 718.2(e) of the Canadian Criminal Code, which states that particular attention should be paid to the circumstances of Aboriginal offenders by sentencing judges. The application of this section has primarily been outlined by two Supreme Court decisions.

In R v. Gladue (1999), the Supreme Court recognized the importance of balancing the needs of communities with the needs of offenders when making a sentencing decision. The court stated the necessity to consider the unique background and systemic factors that may have played a part in an Aboriginal-Canadian offender arriving before the court. In circumstances where these factors are significant, the court encouraged sentencing judges to consider whether imprisonment would serve to deter, or denounce crime in a manner that was meaningful to the community. In R. v. Wells (2000), the Supreme Court clarified that the poor social and economic conditions faced by Aboriginal-Canadians would not definitively result in a more lenient outcome, but rather should be considered in conjunction with the other principles of sentencing (deterrence and denunciation) outlined in the Criminal Code.

While Bill C-41 was formulated to provide the courts with an alternative to the incarceration of Aboriginal-Canadians, this legislation has presented judiciaries with a number of issues. Difficulty interpreting this law has resulted in offenders with similar offences and criminal histories receiving very different sentences. For instance, the 
concept of Aboriginal identity is complex given that Canada's previous policies have encouraged the assimilation and displacement of Aboriginal-Canadians. Although it is clear that sentencing judges require information concerning the life circumstances of an offender, little direction has been provided with regards to which unique factors should be considered, how the information can be obtained, or the amount of information that is required. Furthermore, questions surrounding who qualifies as an Aboriginal-Canadian, the availability of remedial measures, and the weight that should be placed on other principles of sentencing remain prominent issues in recent court decisions involving Aboriginal-Canadians (e.g., R. v. Collins [2011]; R. v. Jensen [2005]; R. v. Thomas [2005]; R. v. Kootenay [2006]).

Thus, while section 7.18(e) has provided both recognition and purported action to the problem of Aboriginal over-representation, the discrepancy between Aboriginal and non-Aboriginal offenders in corrections continues to grow (Roberts \& Melchers, 2003). Since 2000, Aboriginal representation in federal corrections has increased from $17 \%$ to $23 \%$, suggesting this reform has made little progress in reducing the number of incarcerated Aboriginal-Canadians over the past decade (Office of the Correctional Investigator, 2013).

Legal scholars propose that much of the differential treatment faced by Black and Aboriginal-Canadians arises from culturally held stereotypes about minority individuals. According to Welch (2007), society tends to associate being Black with hostility, aggressiveness, and dangerousness, with Black individuals being more likely than any other race to be characterized as violent criminals (Correll, Park, Judd, \& Wittenbrink, 2007). Likewise, Aboriginal-Canadians are also frequently viewed in a negative light, 
often being perceived as dishonest, unintelligent, poor, and addicts (Corenblum \& Stephan, 2001; Pfeifer \& Ogloff, 2003). These unsettling findings call for a better understanding of the role defendant race plays in the decision-making process of jurors in Canada.

\section{Juror Decision-Making}

The prevalence of stereotypic beliefs can have no greater impact on an individual than in the criminal justice system. Over the years, researchers have used various theoretical models to offer explanations as to how jurors process information and arrive at their final decision. These theories are rooted in cognitive processing and attempt to clarify means by which personal beliefs may affect juror decision-making.

Stereotypes. Juror decision-making is a complex cognitive process in which individuals combine information with their existing cognitive beliefs to draw inferences and reach conclusions about a defendant. Selected to participate in the judicial process, jurors carry with them life experiences, knowledge, and acquired beliefs. Stereotypes are essentially beliefs or opinions about the attributes associated with a specific grouping or category of individuals (Schneider, 2004). Accordingly, stereotypes are culturally shared beliefs that cause people to interpret individual factors as generalities (Fiske, 1998). For example, race is one of the multiple visual cues that individuals interpret as a social classifier. Correspondingly, racial stereotypes are cognitive beliefs about an individual's character based on being a member of a particular racial group (Fiske, 1998).

Stereotyping is an efficient means of unconsciously simplifying the decisionmaking process under complex or uncertain situations. More specifically, social cognition research has demonstrated that stereotypic beliefs have a bearing on what information is 
sought out (Erber \& Fiske, 1984), attended to (Zarate \& Smith, 1990), and encoded (Macrae, Hewstone, \& Griffiths, 1994). A study by Erber and Fiske (1984) suggests that people tend to disregard information that is inconsistent with their preconceptions and focus on information that confirms their beliefs. For instance, Jones and Kaplan (2003) found that White mock jurors were more likely to recall information that was consistent with a guilty verdict when the defendant was Black as compared to when the defendant was White. Similarly, individuals tend to encode and recall information that is stereotypically congruent. Eberhardt, Goff, Purdie, and Davies (2004) found that participants were more likely to falsely identify and perceive the defendant as criminal when the defendant possessed traits that were stereotypically characteristic of Black individuals (e.g., broad nose, thick lips, dark skin).

The distinction between stereotypes and prejudice is analogous to the distinction made between beliefs and attitudes. Stereotypes are beliefs about the character of an individual based on a general observation (Fiske, 1998). In contrast, prejudice represents a tendency to evaluate a certain group with some degree of favour or disfavour. Over time, unconscious racial stereotypes begin to influence conscious processes, which can lead to prejudice. Once a negative stereotype is adopted, hostile attitudes towards a social group or a member of that social group can begin to form (Fiske, 1998). Thus, stereotypes may hinder jurors' abilities to form individual impressions, alternatively causing jurors to make dispositional attribution-related inferences about the cause of a crime.

Attribution theory. Attribution theory is a perspective proposed by Heider (1982) to help explain how individuals perceive and rationalize others' behaviour. 
Individuals are thought to have a mental schema that they use to infer possible causes for a given event. These explanations of behaviour can be categorized as internal or external. Internal attributions ascribe the causes of behaviour to personal dispositions (i.e., personality characteristics), whereas external attributions ascribe the cause of the behaviour to environmental factors (i.e., situational factors).

Elaborating on Heider's insight, Gordon (1990) proposed an attribution-based explanation for the ways in which defendants are viewed in criminal trials. It was hypothesized that people assign explanations for the defendant's behaviour based in large part on the typicality of the crime. He reasoned that if a defendant is charged with a crime thought to be typical of that person's race, jurors would form internal attributions regarding the criminal behaviour, leading to harsher judgements. To test this explanation, Gordon (1990) collected data from 96 participants who read a trial transcript in which the defendant's race was congruent (e.g., White defendant charged with embezzlement) or incongruent (e.g., White defendant charged with burglary) with the crime stereotype. As predicted, mock jurors perceived the crime as being due to internal factors when the crime was stereotype-consistent, but was attributed to external factors when the defendant's race was incongruent with the crime.

Further support for the attribution theory can be found in a more recent study done by Jones and Kaplan (2003). Assessing attributional judgements made by European American mock jurors, the researchers found that crimes consistent with the race stereotype (i.e., auto theft for the Black defendant, embezzlement for the White defendant) of the defendant were attributed to more stable causes of behaviour and produced more convictions with harsher sentences. Additionally, defendant race was 
found to influence mock jurors sentencing decisions, such that Black defendants, regardless of the crime, were sentenced more harshly than the White defendants. This study extends previous work by Gordon (1990) by demonstrating that attributional processes may be combined with biased beliefs to account for various explanations of a defendant's behaviour, resulting in different verdict outcomes.

Aversive racism theory. As Canada becomes an increasingly pluralistic society, overtly racist attitudes and beliefs have become socially less acceptable. In support, research suggests that White individuals view minorities in a more positive light than in the past (Gaertner \& Dovidio, 2005). Despite this decrease in reported bias, minority defendants continue to feel that stereotypic beliefs are persistent and problematic. Gaertner and Dovidio (1986) propose that the decrease in racist beliefs is not due to changes in attitudes but rather the desire to appear unprejudiced. Based on this theory, individuals who construct their opinion based on racial appearance can be categorized as either dominative or aversive racists. Dominative racists are considered to be individuals who are openly and overtly expressive about their prejudicial attitudes. In contrast, aversive racists support principles of racial equality while sometimes feeling anxious or uncomfortable in the presence of minority individuals due to implicit, autonomic views. It is suggested that aversive individuals will often alter their behaviour when engaging with minority group members due to conflicting emotions.

The aversive racism theory has frequently been presented as a contributing factor in the context of workplace hiring (Dovidio \& Gaertner, 2000), affirmative action (Dovidio \& Gaertner, 1996) and legal decision-making (Dovidio, Smith, Donnella, \& Gaertner, 1997). For instance, in a study involving an employment scenario, participants 
displayed racial equality by judging the Black and White candidates fairly when qualifications were clearly strong or weak (i.e., choosing the candidate with strong qualifications, regardless of race), but were more likely to endorse a White applicant when the appropriate candidate was more ambiguous (Dovidio \& Gaertner, 2000). Consistent with this research, Hodson, Dovidio, and Gaertner (2002) found similar patterns of aversive racism in university selection recommendations. Compared to White applicants, Black applicants were endorsed less frequently when credentials were ambiguous. In contrast, participants recommended Black and White candidates with unambiguous qualifications equally. Furthermore, participants scoring higher on measures of prejudice were more likely to provide an extensive justification for denying the application of a Black participant with ambiguous results than were lower-scoring participants. These findings suggest that prejudicial views may have influenced how participants viewed applicants, holding Black applicants with ambiguous results to different standards than White applicants with the same marks.

In a trial setting, aversive racism may influence jurors' causal attributions as well as their verdict. Criminal trials are inherently ambiguous. Weak criminal cases are unlikely to be prosecuted, and very strong cases are likely to result in a guilty plea. In these situations of ambiguity, where the guidelines for appropriate social behaviour are unclear, the unconscious beliefs of aversive racists may contribute to discriminatory behaviour. Thus, racial bias and stereotyping have not disappeared, but rather continue to operate in a more subtle fashion.

\section{Race and Legal Judgements}


In assessing a defendant's culpability, research suggests that jurors often rely on physical attributes rather than the content of the trial to evaluate a defendant's guilt. Studies assessing the influence of a defendant's appearance have consistently demonstrated that factors such as gender (Thompson, Merrifield, \& Chinney, 2011), age (Higgins, Health, \& Grannemann, 2007), and attractiveness (Mazzella \& Feingold, 1994) influence mock juror judgements. A separate body of literature has also shown that defendants may be perceived differently based on their racial appearance. The influence of defendant race has been researched almost exclusively in the United States, and has focused primarily on Black and White defendants. While some studies suggest that race has no reliable effect on White jurors (e.g., McGuire \& Bermant, 1977; Skolnik \& Shaw, 1997), others have demonstrated bias against Black defendants (e.g., Sommers \& Ellsworth, 2000; Sweeney \& Haney, 1994). In an attempt to summarize the American Black and White racial bias literature, three meta-analyses have been previously conducted (Mazzella \& Feingold, 1994; Mitchell, Haw, Pfeifer, \& Meissner, 2005; Sweeney \& Haney, 1992). While each of these meta-analyses sought to resolve inconsistencies in the empirical literature, they resulted in differing conclusions.

Sweeney and Haney (1992) were among the first to conduct a meta-analysis examining the effect of defendant race on sentencing decisions. Their analysis focused on 14 studies, with 19 effect sizes and 2,386 White participants. Across studies, defendant race was found to have a small, yet significant, effect on sentencing decisions such that White jurors sentenced Black defendants more harshly than same-race defendants. These findings are consistent with the capital punishment literature, which has demonstrated that Black defendants are sentenced to death more frequently than are White defendants 
by White jurors (Lynch \& Haney, 2011). A more recent meta-analysis by Mitchell, Haw, Pfeifer, and Meissner (2005) sought to determine whether juror bias extended to verdict decisions as well. Seventy-one studies assessing verdict and sentencing decisions were included. Consistent with Sweeney and Haney (1992) analyses revealed a small but consistent effect of defendant race. Overall, Black defendants were found to be convicted more often and sentenced more harshly than similarly situated White defendants.

Interestingly, manifestations of racial bias are not limited to verdict and sentencing disparities. Studies assessing the accessibility of stereotypes have found that in shooting paradigms, participants were more likely to shoot an unarmed man if he was Black compared to White and exhibited more caution with White armed suspects (Correll, Park, Judd \& Wittenbrink, 2002; Correll, Park, Judd \& Wittenbrink, 2007). Similar biases have also been demonstrated in the jury selection literature. On the whole, society seems to be more skeptical of Black prospective jurors. Sommers and Norton (2007) had participants assume the role of a prosecuting attorney that was responsible for selecting jurors to sit on a robbery and aggravated assault trial with a Black defendant. Participants were told that they would be able to dismiss a certain number of prospective jurors. Jurors could be dismissed if it was believed that they would be biased or unsympathetic to the prosecution's case. To make an informed decision, participants were provided with detailed descriptions of prospective jurors, who were either described as being White or Black. Overall, the race of the prospective juror was found to influence participants' rates of dismissal, such that the Black prospective juror was struck down significantly more often than the White prospective juror. While participants rarely cited 
race as their motive, these findings suggest that Black prospective jurors are perceived to be less impartial when faced with a trial involving a Black defendant.

However, not all studies have demonstrated bias towards Black individuals. Mazzella and Feingold (1994) analyzed 29 studies, with 63 effect sizes, and found no effect of defendant race. Rationalizing these conflicting results, some have criticized the methodology of the latter study. Contrary to other meta-analyses, Mazzella and Feingold (1994) neglected to distinguish between White and Black mock jurors in their comparison. This limitation is pertinent because research suggests that Black mock jurors tend to demonstrate more same race leniency than White mock jurors (Sommers \& Ellsworth, 2000). Had Mazzella and Feingold (1994) accounted for juror race, it is much more likely that a significant effect for defendant race would have been found.

In an effort to determine whether verdict and sentencing disparities extend to other races (i.e., Native Americans), Struckman-Johnson, Struckman-Johnson, and Miller (2008) analyzed the responses of 80 university students. After reading a trial summary of a robbery case committed by a defendant with a Native American or a White European surname who was intoxicated in half of the cases, participants were asked to render a verdict and sentencing decision. Race was not found to be an influential factor in the judgements of mock jurors, such that guilt and sentencing ratings for the Native American defendant and the White defendant did not differ. However, the intoxicated Native American defendant did receive the highest number of guilt verdicts, supporting the "drunken Indian" bias. This intoxication bias did not occur for the White defendant. Furthermore, participants who scored higher on racial bias scales provided harsher guilt ratings to the Native American defendant, whereas egalitarian participants gave higher 
guilt ratings to the White defendant. These trends may indicate that race effects could have been negated due to mock jurors' efforts not to appear biased toward the Native American defendant.

Additional research investigating the effects of defendant race on juror decisionmaking in Canada suggests that conflicting findings are not restricted to American studies. In Schuller, Kazoleas, and Kawakami’s (2009) study, 230 Canadian university students were asked to read a trial summary of an embezzlement or drug trafficking case. Within the two case scenarios, the race of the defendant varied, Black or White. Strengthening Mitchell et al's. (2005) findings, across dependent measures and regardless of the crime, the Black defendant was judged more harshly than the White defendant. More specifically, participants were more inclined to render a guilty verdict, and be confident in their decision, when the defendant was Black as compared to White.

In contrast, Bagby, Parker, Rector, and Kalemba (1994) demonstrated the opposite effect; mock jurors displayed bias toward the Black defendant, finding the White defendant guilty more frequently after viewing a sexual assault trial. A possible explanation for the conflicting results may be the mode in which the cases were presented. While most studies to date provided mock jurors with written transcripts, Bagby and colleagues (1994) presented videotaped presentations. The researchers suggest that the visual cues may have highlighted the race of the defendant, prompting a socially desirable response by which jurors overcompensated in their decision-making.

With regards to Aboriginal-Canadian defendants, Pfeifer and Ogloff (2003) revealed that White Canadians have negative stereotypes of this racial group. Within the context of a sexual assault trial, mock jurors perceived the Aboriginal-Canadian 
defendant to be subjectively guiltier (as measured on a continuous scale) than the White defendant, resulting in harsher sentences. However, this effect seemed to only hold in the absence of judicial instructions. In a more recent analysis by Maeder and Burdett (2013), mock jurors displayed bias towards an Aboriginal defendant with the use of both a dichotomous verdict and judicial instructions. More specifically, mock jurors assigned significantly more guilty verdicts to the Aboriginal-Canadian in comparison to the White or Black defendant after reading about a robbery trial. These results reinforce the stereotypes found by Pfeifer and Ogloff (2003) and strengthen the notion that Canadians are also affected by the ideologies of aversive racism.

Collectively, findings from both countries suggest that a defendant's race may be taken into consideration during the decision-making process of a trial, and has the potential to influence juror judgements. While findings in the racial bias literature are inconsistent, contradictory studies suggest that other aspects of the criminal trial, such as the overall prominence of racial issues, may interact with a defendant's race to account for conflicting outcomes.

\section{Race Salience}

Race salience refers to the overall prominence of racial issues during a trial (Sommers \& Ellsworth, 2000; 2001; 2009). Researchers in this area have argued that the more salient the topic of race is made during a trial, the less likely White mock juror judgements will be influenced by racial biases. Drawing from the aversive racism theory, when race is a salient issue in the trial, the possibility of engaging in discriminatory behavior is also salient for White mock jurors. However, when race is not a salient issue, White mock jurors are less self-conscious about appearing racist and are therefore more 
likely to employ their implicit negative stereotypes and engage in harsher judgements against Black defendants. Therefore, highlighting racial issues during the trial should make White mock jurors more aware of potential biases, thus correcting for them and leading to equivalent verdicts for own-race and other-race defendants.

To investigate whether the inconsistencies found in the aforementioned racial bias literature were a result of race salience, Sommers and Ellsworth (2000) conducted two studies that compared Black and White mock jurors' guilt judgements for a variety of charges. In the first study, 64 predominantly White participants reviewed five trial summaries involving blatant racial issues. For instance, participants read of a case where an assault occurred as a result of racial slurs. While race was salient in all of the scenarios, the race of the defendant was manipulated as either Black or White. Findings indicated that White mock jurors were not influenced by the defendant's race; however, Black mock jurors recommended higher guilt ratings for White defendants than for Black defendants. While Sommers and Ellsworth (2000) speculate that White and Black jurors experience the same tendencies to perceive own-race members more favorably, these findings suggest that perhaps only White individuals are prompted by society to repress the expression of biased attitudes.

In the second study, Sommers and Ellsworth (2000) manipulated the salience of racial issues in the stimulus trial. In the race-salient condition, racial issues were prominently featured through the use of racial epithets uttered during the crime. In the non-race-salient condition, demographic information presented before the trial identified the race of the defendant, but no reference to race occurred at any point during the trial proceedings. Analyses revealed similar overall trends. When racial issues were 
highlighted in the trial summary, White jurors appeared non-prejudiced, whereas Black mock jurors demonstrated same-race leniency. In trials where race was not a prominent issue, White mock jurors were more likely to convict and suggest a longer sentence for the Black defendant. These results suggest that when racial issues are called to the forefront, White jurors are reminded of their desire to appear unbiased. In contrast, Black mock jurors appear to automatically perceive race to be a salient component in trials involving a Black defendant, demonstrating leniency for the racialized defendant in both versions of the trial.

In an attempt to extend their findings to other types of crimes, Sommers and Ellsworth (2001) approached 196 White American participants in the waiting area of an international airport. Mock jurors were presented with a written trial summary of an assault case involving two basketball teams. The race salience of the trial was manipulated through the use of a defense witness. In the race salient conditions, an assistant coach testified that the defendant was only one of two White (or Black) players on the team, and that the fight was a result of racial tension. In the non-race salient conditions, the witness provided a race-neutral explanation by suggesting that the defendant only had one close friend on the team. As predicted, White mock jurors put forth a socially desirable response when race was featured as a prominent issue in the trial. However, when race was not a featured issue in the trial, White mock jurors demonstrated racial bias. More specifically, White mock jurors provided more guilty verdicts and longer sentencing decisions for Black defendants than White defendants in the non-race-salient condition. 
Similar studies have extended these findings by manipulating race salience in different manners. For instance, Bucolo and Cohn (2010) presented participants with a written trial summary describing an assault case that was interracial in nature (i.e., the defendant was Black and the victim was White, or the defendant was White and the victim was Black). The trial summaries included opening and closing statements from the defence attorney emphasizing the race of the defendant and framing the crime in racially-charged terms in half of the conditions. Contrary to previous findings, White participants' ratings of guilt did not significantly differ when race was not made salient. However, when racially charged statements were included in the defence attorney's closing arguments, White mock jurors' ratings of guilt were significantly lower when the defendant was Black.

To determine whether race salience could reduce White juror bias even for individuals who reported high levels of racism, Cohn, Bucolo, Pride, and Sommers (2009) assessed the association between racism and juror verdicts. The researchers had participants view an edited episode of CourtTV that depicted an attempted vehicular homicide committed by a Black male. During the trial, participants viewed testimony from either a White or Black victim. In keeping with previous research, race salience was manipulated through the use of testimony that highlighted racial slurs uttered during the crime. Consistent with Sommers and Ellsworth's (2001) findings, jurors' racial biases were only associated with verdict judgements when race was not made salient. Jurors rationalized their judgements to find the defendant not guilty by evaluating the defence's case as stronger in the race salient condition as compared to the non-race salient condition. With regards to racial attitudes and verdicts, higher ratings on the overt racism 
measure predicted higher ratings of defendant guilt in the non-race-salient condition. These findings suggest that regardless of jurors' levels of racism, making racial issues salient during trials helps to reduce biased White juror judgements.

Together, the race salience literature helps to explain some of the inconsistent results found in the racial bias literature. More specifically, the influence of a defendant's race on White mock jurors seems to be contingent on whether or not racially charged issues are featured prominently in a trial. While these findings are encouraging, they must also be interpreted with caution. The effects of race salience found in the current literature appear to rest on the aversive racism framework, which is a result of years of racial prejudice and discrimination towards Black individuals in the United States (Sommers, 2007). When race is not featured as a prominent issue in a trial, White jurors are more inclined to render judgements without being mindful of the fact that race may have played a role in their decision-making process. Sommers and Ellsworth (2009) express that the influence of raising racial issues during trial does not eliminate stereotypical judgements by jurors, but rather reduces the discriminatory judgements against Black defendants. Furthermore, the effect of raising race as a salient issue during trial is not said to have a similar impact on all juror-decision making. For instance, while Canada and the United States are similar in many aspects, a distinction can be made between the two countries with regards to their racial diversity and prior race relations (Statistics Canada, 2008; U.S. Department of Commerce, 2012; Vickers, 2002). Thus, it remains unclear whether race salience manipulations would have the same effect on Canadian jurors and whether other minority members, such as Aboriginal-Canadians, would benefit from such a manipulation (Cohn et al., 2009). Lastly, researchers studying the effects of race 
salience on juror decision-making have generally operationalized the term in the same manner: whether or not the crime in question was racially charged. To date, only one study by Sommers (2006) has examined other possible forms of race salience outside of trial proceedings. In this study jurors were presented with racially relevant or racially neutral voir dire questions. A voir dire is a prelimary questioning period prior to trial that is said to provide legal professionals with the opportunity to identify jurors who are likely to demonstrate biases (Sommers, 2006). Sommers (2006) found that jurors who were presented with the race-relevant voir dire were more likely to attribute the defendant's behaviour to external attributions and less likely to find the defendant guilty, compared to jurors in the race neutral condition. From a legal perspective, these findings suggest that posing racially charged voir dire questioning is an effective mechanism to reduce White juror bias. Making race salient helped to remind jurors of their desire to be (or appear) egalitarian and led to deeper informational processing, resulting in external attributions for the defendant's behaviour (Sommers, 2006).

\section{Racially Charged Media}

One possible approach that remains unexplored is the influence of racially charged media on juror judgements. Researchers addressing media exposure have generally focused their efforts on understanding the influence of pre-trial publicity on juror judgements. Pretrial publicity commonly refers to media coverage, in the form of internet, newspaper, television, or radio, which may lead prospective jurors to form an opinion of a case prior to a trial (Kovera, 2002). Research has consistently demonstrated that pre-trial publicity negatively affects verdict choice, perceptions of the defendant, and other aspects of the criminal trial (Steblay, Besirevic, Fulero, \& Lorente, 1999). The 
media is a powerful socialization agent that has acquired a central role in our daily lives and has become one of the primary sources of everyday information. Political scholars have argued that the attention media gives to particular social issues influences our evaluations of the topic's importance. The framework typically used to account for this effect is known as agenda-setting (Iyengar \& Kinder, 1985; McCombs \& Shaw, 1972). Agenda-setting relies on a cognitive process known as accessibility (Iyengar \& Kindart, 1985). It assumes that individuals make decisions based on information that is easily accessible and retrievable from memory (McCombs \& Shaw, 1972). In its most basic sense, agenda-setting is the media's ability to influence our evaluations of an issue's importance by increasing the salience of the issue. The cognitive accessibility of an issue is increased by either featuring the story frequently or framing it as a socially relevant matter.

Literature examining the influence of agenda-setting and its effect on juror decision making is relatively sparse. Kovera (2002) was the first to investigate the agenda-setting theory in a legal context. The purpose of the study was to determine whether exposure to a news story about rape influenced participants' expectations for the type of evidence they required before convicting a defendant of the offence. Before being given the trial stimulus, participants were exposed to one of three news stories that either induced or did not induce thoughts about rape. The news stories meant to induce thoughts about rape had either a pro-defence orientation (i.e., favorable to the plight of the defendant) or a pro-prosecution orientation (i.e., favorable to the plight of the victim). Similar to the race salience literature, increasing the cognitive accessibility of rape significantly altered the type of evidence jurors required to find the defendant guilty. That is, jurors who were 
exposed to a pro-defence news story about rape requested more inculpatory evidence than jurors who were exposed to pro-prosecution media or those not exposed to rape media. Similarly, exposure to a pro-defence news story also led jurors to assign a lower probability of guilt to any defendant accused of rape. This research demonstrates that agenda-setting can influence jurors' guilt perceptions by increasing the salience of particular issues.

In following, priming race as a relevant social issue may be a practical suggestion for the amelioration of unconscious racial bias among jurors. Fein, Morgan, Norton and Sommers' (1997) research has provided indirect support for this notion. In this study, jurors were asked to read a trial summary of a criminal assault case. Prior to reading the trial summary, half of the mock jurors were exposed to inflammatory news articles about the defendant. Among jurors exposed to the pretrial publicity, some read articles that raised suspicion about the authenticity of the incriminating information. The defendant in the suspicious articles was identified as a Black male in half of the articles. Overall, exposure to pretrial publicity was found to significantly increase guilty verdicts, unless the articles caused jurors to question the media's racist motives. More specifically, mock jurors' suspicions about the articles and prosecution's conceivably racist motives undermined the otherwise strong pretrial publicity effects. Thus, White mock jurors who were exposed to suspicious news articles about a Black defendant were more lenient in subsequent trial judgements compared to mock jurors who were not exposed to the same stimuli. These findings support previous work by Sommers and Ellsworth $(2000 ; 2001)$ and suggest that the media can be a powerful tool of persuasion. Thus, to the aim of 
further combating racial bias among jurors, it is necessary to investigate the influence of racially charged media on juror judgements.

\section{Current Study}

While various studies have indicated that the influence of a defendant's race on juror decision-making is contingent on whether the trial is racially charged, there is little research surrounding the effects of racially charged media on verdicts or causal attributions. Furthermore, much of the research regarding the effects of racial bias on juror decision-making has focused on American White and Black defendants. Thus, the extent to which prejudice towards Aboriginal-Canadians may influence jury decisionmaking still remains largely unknown.

The purpose of this study was to understand how a defendant's race and racially charged media affect juror decision-making in Canada. Specifically, this study sought to determine whether exposure to a racially charged news article (general, or specific to the defendant's race) make racial biases more accessible to the decision-maker, thereby increasing the perceived importance of appearing non-prejudiced. Knowing how a defendant's race and racially charged media affects jurors' decisions will enable us to identify biases pertaining to minority defendants. With a better understanding of such biases and attitudes, the legal system could be more effective in maintaining a defendant's Charter right to an impartial trial.

\section{Hypotheses}

\section{Hypothesis \#1}

There would be a relationship between racial bias and trial decisions (Dovidio, Smith, Donnella, \& Gaertner, 1997). Specifically, higher endorsement of negative 
stereotypes [as measured by trait ratings] would be associated with higher levels of guilt certainty, longer sentences, and more internal causal attributions for the Black and Aboriginal-Canadian defendants.

\section{Hypothesis \#2}

There would be an effect of defendant race on trial decisions (verdict, sentencing, causal attributions). Based on culturally held stereotypes, Black and Aboriginal-Canadian defendants will be found guilty more often and given harsher sentences than White defendants (Mitchell, Haw, Pfeifer, \& Meissner, 2005; Pfeifer \& Ogloff, 2003).

Hypothesis \#2a: The relationship between defendant race and trial decisions would be reduced or eliminated in the conditions where participants had been exposed to racially charged media. Since the racially charged media was expected to increase the cognitive accessibility of racial issues in the community, White mock jurors should demonstrate more lenient trial judgements when they read a racially charged article in comparison to an article wherein race was not an issue (Sommers \& Ellsworth, 2001). While both the race specific and general race articles feature prominent racial overtones, this effect was predicted to be strongest for jurors presented with the race specific article as it exclusively related to the race of the defendant.

\section{Method}

\section{Participants}

Participants were 210 Canadian jury-eligible community members recruited through a Qualtrics panel ${ }^{1}$. The sample was made up of $86(41 \%)$ men and $124(59 \%)$

\footnotetext{
${ }^{1}$ A Qualtrics panel is a crowd-sourcing platform that randomly selects participants from the Qualtrics database to participate in a survey. The Qualtrics database is comprised of 3000 Canadian workers who were recruited through online advertisements.
} 
women, with a mean age of $48(S D=15.82)$. The sample was predominantly White $(178$, 84.8\%), with 13 individuals (6.2\%) identifying as Asian, 5 (2.4\%) as Black, 5(2.4\%) as East Indian, $4(1.9 \%)$ as Aboriginal-Canadian, $1(.5 \%)$ as Middle Eastern, and $4(1.9 \%)$ individuals selecting other. Participants took approximately 33 minutes to complete the survey.

\section{Materials}

News article. Participants each read a news article from The Canadian Press, reporting on the healthcare system in Canada. For the race salient conditions, participants were presented with an article addressing the differential treatment Canadians face in urban healthcare centers. The race salience of the article was manipulated through the racial content included. Thus, participants in the race salient conditions received either a race specific (see Appendix A) or general race (see Appendix B) version of the article. In the race specific condition the article was entitled, "Aboriginal/Black Canadians face racism, stereotyping in urban healthcare centers". Participants in the general race condition read the same report, except the specific race was replaced by "minorities". Finally, participants in the race neutral condition read an article entitled, "Health care of top importance to Canadians" (see Appendix C).

Article review. As a distracter task, participants were asked to review the articles' readability and suggest the intended audience. To ensure participants read the article thoroughly, they were also asked about the intended purpose of the article (see Appendix D).

Trial transcript. Participants were presented with a written trial transcript involving two fabricated offences (dangerous operation of a motor vehicle and impaired 
driving causing bodily harm) committed by a male defendant with a White, Black, or Aboriginal-Canadian surname. Each transcript was also accompanied by a photograph of the defendant. The transcript highlighted the court proceedings, consisting of statements, arguments, and questioning from both the Crown and the Defence regarding the defendant's charges (see Appendix E).

Jury instructions. To inform mock jurors' decisions, participants were provided with the Criminal Code criteria for the charges, as well as instructions regarding the burden of proof and reasonable doubt (see Appendix F).

Dichotomous verdict. Participants were asked to issue a verdict recommendation of either guilty or not guilty for each of the offences (see Appendix G).

Verdict confidence. On a scale ranging from 1 ("Not at all confident") to 10 ("Very confident") participants were asked to indicate the degree of confidence they placed in each of their verdicts (see Appendix G).

Sentence length. If participants found the defendant guilty of either offence, they were asked to provide a sentencing recommendation for the crime on a scale from 1 ("No punishment") to 9 ("Maximum punishment allowed by law"). Although jurors do not make sentencing recommendations in trials, the sentencing decisions were considered in part as another measure of bias (see Appendix G).

Juror questionnaire. The juror questionnaire consisted of a range of questions including the perceived strength of the Crown's and Defence's cases, and participant demographic information (such as age, gender, race, education, and political affiliation; see Appendix G). 
Causal attributions. Participants were asked about their perceived source of the criminal behaviour with regards to three dimensions (locus of control, stability, controllability). Answers were specified on scales ranging from 1 to 9 . Responses to the nine questions were then averaged to produce an overall measure of causal attribution. Participants who did not believe the defendant committed the crime were able to select the not applicable options (see Appendix G).

Trait ratings. To assess cultural and personal racial views, 20 trait ratings were collected on 7-point rating scales (see Appendix G). Participants were asked to indicate the degree to which the adjectives listed (e.g., violent, honest, impulsive) reflected the cultural stereotype of White/Black/Aboriginal-Canadians. Since cultural stereotypes can be dissociated from personal stereotypes for low-prejudiced individuals (e.g., Krueger, 1996), using the same list, participants were also asked to indicate the degree to which the adjectives listed represented part of their personal stereotypes towards White/Black/Aboriginal-Canadians. The ratings for the 20 items were summed, with positive adjectives reverse coded, resulting in higher scores reflecting more racially biased attitudes.

This list was compiled from an earlier stereotype measure employed by Katz and Braly (1993). Additional adjectives were also added to the list based on information from Devine and Elliot (1995), as well as Flemming (2006). The adjectives were coded by three independent raters for having either criminal or noncriminal connotations. Interrater reliability was then calculated using the kappa coefficient to determine consistency among raters. The kappa coefficients ranged from .78 to 1.00. These ratings were considered acceptable and therefore all variables were retained. There were two 
instances of disagreement for which the adjectives (i.e., suspicious, uneducated) were deemed to have a criminal connotation based on majority agreement.

Symbolic racism scale. A modified version of the Symbolic Racism Scale 2000 was used as a second explicit measure of racial bias (Henry \& Sears, 2002; see Appendix $\mathrm{G})$. The scale was originally designed as a 16-item measure with responses ranging from 1 ("strongly disagree") to 4 ("strongly agree"), with several items reverse coded. The items were intended to capture the 4 different themes of symbolic racism, including: (1) Blacks no longer face much prejudice or discrimination, (2) the failure of Blacks to progress results from their unwillingness to work hard enough, (3) Black are demanding too much too fast, (4) Blacks have gotten more than they deserve. In the modified version of the scale, Henry and Sears (2002) recommended excluding 8 items based on their psychometric properties, resulting in an 8-item scale as the final measure. This scale has demonstrated good internal consistency ( $\alpha=.75$ to $\alpha=.79$ ) and test-retest reliability for White participants ( $r=.68$ over a two-year interval; Henry \& Sears, 2009). The scale has also demonstrated good predictive and discriminant validity, correlating strongly with Whites' attitudes toward racial policies, and poorly with political dispositions and traditional racial attitudes.

The 8-item scale was tailored in this study to measure symbolic racism against both Black and Aboriginal-Canadians by replacing the term "Black" with "AboriginalCanadian" in relevant conditions. Two additional items were also included so that the scale appropriately corresponded with the research question at hand. The two additional items were: "there are times when a trial judge should take an offender's Black/Aboriginal-Canadian status into account when making sentencing decisions" and 
"the over-representation of Blacks/Aboriginal-Canadians in prisons is a major social problem in Canada today". The final 10-item scale demonstrated acceptable reliability ( $\alpha$ $=.65)$ in this study.

\section{Procedure}

Upon initial recruitment, participants were directed to the online survey software, Qualtrics. Participants were informed that this was a study concerning "juror decisionmaking" but were not specifically informed about our interest in how a defendant's race and racially charged media affects juror decision-making.

Once informed consent had been obtained, participants were randomly assigned to a racially charged (general or specific to the defendant's race) or racially neutral article. To ensure participants read the article, they were asked to identify the intended purpose and review the article's readability. Following the article, participants read a trial transcript describing a dangerous operation of a motor vehicle (DOM) and impaired driving causing bodily harm case. Participants were then asked to make a judgement about the defendant's guilt with regards to the two charges based on the evidence provided, and rate the confidence of their decisions. If guilty verdicts were suggested, participants were asked follow-up questions regarding the recommended sentence lengths. Regardless of their verdict decisions, participants were also asked to complete a brief questionnaire about their impressions of the evidence and testimonies presented at trial, as well as possible causes for the crime. At this point, cultural and personal beliefs about the defendant's racial group were assessed using trait assessments. Finally, participants were asked to complete a modified version of the Symbolic Racism Scale 
(Henry \& Sears, 2002) and provide demographic information such as gender, age, race, and political affiliation.

Manipulation/attention checks. Without reference to preceding trial materials, participants were asked to identify the race of the defendant, as well as other details in the case, such as the defendant's occupation. Participants who failed one or more of the manipulation/attention checks were removed from subsequent analyses.

\section{Design}

A 2 [Defendant race: Black, Aboriginal-Canadian], x 3 [Race salience: Specific, General, Neutral], between-subjects factorial design was used to examine verdict and sentencing decisions as well as participants' causal attributions for the defendant's behaviour. A White/Race Neutral control condition was used for comparison purposes.

Variable creation. To obtain a sensitive measure of guilt, a guilt certainty measure was created by multiplying the dichotomous verdict $(-1=$ not guilty, $1=$ guilty) by verdict confidence $(1=$ completely unconfident, $10=$ completely confident $)$. The variable ranged from -10 (very confident that the defendant was not guilty) to 10 (very confident that the defendant was guilty). A measure of verdict certainty is widely accepted and commonly calculated within jury research (e.g., Cohn, Bucolo, Pride, \& Sommers, 2009; Sommers \& Ellsworth, 2001).

\section{Results}

Prior to analyses, data screening was performed to reduce outliers and test assumptions. To assess univariate outliers, participants' values on each of the dependent measures were converted to their standardized equivalents. Given our large sample size, participants with z-scores over a value of 3.29 were considered outliers (Cohen, Cohen, 
West, \& Aiken, 2003). There were no univariate outliers identified on the verdict certainty, sentence, causal attributions, cultural stereotypes, or racism measures. One outlier (id:Y0jMV) was manually changed to reflect a value of .2 more than the next highest score on the personal stereotypes scale (Cohen et al., 2003). Since each participant completed these measures separately, their responses were presumed to be independent of one another.

To evaluate normality, the data file was split by defendant race and article type. Descriptive statistics were run to obtain the skewness and kurtosis for each dependent variable. The skewness and kurtosis for the verdict certainty, sentence, causal attributions, cultural stereotypes, and racism measures were within range of acceptable values from -3.29 to +3.29 , suggesting normal distributions (Kutner, Nachtsheim, Neter,

$\& \mathrm{Li}, 2005)$. Both the skewness (3.37) and kurtosis (4.04) were outside of the acceptable range for personal stereotypes in the Aboriginal race specific condition. However, this was not a concern as both the t-test and omnibus test are fairly robust to deviations from normality (Tabachnick \& Fidell, 2007).

To examine homoscedasticity, a Levene's test was used to assess similarities between the group variances. The variance between conditions differed significantly on the impaired driving verdict certainty measure, indicating heteroscedasticity, $F(6,203)=$ $2.22, p<.05$. The homogeneity of variance assumption held for all other measures.

\section{Negative Racial Stereotypes and Jurors' Trial Decisions}

Correlation analyses were run separately for each defendant race to address Hypothesis 1, which examined whether there was a relationship between negative racial stereotypes and mock jurors' trial decisions (verdicts, sentencing, causal attributions). 
For the Black defendant, a higher endorsement of negatives stereotypes was positively correlated with higher levels of guilt certainty for both the DOM $(r=.28, p<.01)$ and impaired driving charges $(r=.29, p<.01)$. Similarly, mock jurors' negative stereotypes towards Aboriginal-Canadians were moderately positively correlated with higher levels of guilt certainty for the DOM $(r=.32, p<.001)$ and impaired driving charges $(r=.39, p$ $<.001$ ), as well as longer sentences (DOM sentence, $r=.38, p<.001$; impaired driving sentence, $r=.37, p<.01)$. Negative stereotypes were also moderately correlated with causal attributions for the Black $(r=-.26, p<.01)$ and Aboriginal-Canadian $(r=-.27, p<$ .01) defendants, such that mock jurors who endorsed negative racial stereotypes were more likely to attribute the criminal behaviour of the Black and Aboriginal-Canadian defendant to internal factors, as compared to situational factors outside of the defendant's control. The endorsement of negative racial stereotypes did not appear to play a role in mock jurors' judgements of White defendants. However, it is possible that these relationships were negated as a result of a lower sample size. As can be seen in Table 1, the correlation values depicting the relationship between racial bias and trial decisions for the White defendant are within the $95 \%$ confidence intervals.

Table 1. Relationships between Negative Personal Stereotypes and Trial Decisions by Defendant Race

\begin{tabular}{|c|c|c|c|c|c|}
\hline $\begin{array}{l}\text { Defendant } \\
\text { Race }\end{array}$ & $\begin{array}{l}\text { DOM Verdict } \\
\text { Confidence }\end{array}$ & $\begin{array}{c}\text { Impaired } \\
\text { Verdict } \\
\text { Confidence }\end{array}$ & $\begin{array}{c}\text { DOM } \\
\text { Sentence }\end{array}$ & $\begin{array}{l}\text { Impaired } \\
\text { Sentence }\end{array}$ & $\begin{array}{c}\text { Causal } \\
\text { Attributions }\end{array}$ \\
\hline White & $\begin{array}{c}.33 \\
{[\text { C.I.: }-.04, .70]} \\
(N=30)\end{array}$ & $\begin{array}{c}.32 \\
{[\text { C.I.: }-.05, .69]} \\
(N=30)\end{array}$ & $\begin{array}{c}.42 \\
{[\text { C.I.: }-.07,1.00]} \\
(N=18)\end{array}$ & $\begin{array}{c}.31 \\
{[\text { C.I.: }-.21, .93]} \\
(N=17)\end{array}$ & $\begin{array}{c}-.30 \\
{[\text { C.I.: }-.11,-.52]} \\
(N=30)\end{array}$ \\
\hline Black & $\begin{array}{c}.28^{*} \\
{[\text { C.I.: } .90, .50]} \\
(N=90)\end{array}$ & $\begin{array}{c}.29^{*} \\
{[\text { C.I.: .10, .50] }} \\
(N=90)\end{array}$ & $\begin{array}{c}.09 \\
{[\text { C.I.: }-.16, .33]} \\
(N=68)\end{array}$ & $\begin{array}{c}.28 \\
{[\text { C.I.: }-.01, .58]} \\
\quad(N=46)\end{array}$ & $\begin{array}{c}-.26^{*} \\
{[\text { C.I.: }-.48,-.06]} \\
(N=90)\end{array}$ \\
\hline Aboriginal & $.32 * *$ & $.39 * *$ & $.38 * *$ & $.37 *$ & $-.27 *$ \\
\hline
\end{tabular}




$$
\begin{array}{ccccc}
{[\text { C.I.: } .13,52]} & {[\text { C.I.: } .20, .59]} & {[\text { C.I.: } .12, .77]} & {[\text { C.I.: } .09, .70]} & {[\text { C.I.: }-.46,-.07]} \\
(N=90) & (N=90) & (N=46) & (N=44) & (N=90)
\end{array}
$$
[C.I.: .09, .70]
$(N=44)$

$* p<.01$

$* * p<.001$

\section{Dichotomous Verdicts}

To determine whether verdicts varied as a function of defendant race, negative racial bias, causal attributions, or racially charged media for either of the charges, two binary logistic regressions were performed (one for the DOM charge, and one for the impaired driving charge). Both defendant race and racially charged media were contrast coded with White and racially neutral media used as reference groups. The dichotomous verdict variables were also dummy coded, with 1 representing guilty verdicts and 0 representing not-guilty verdicts. For the DOM charge, a test of the full model against a constant-only model yielded significant findings, $\chi^{2}=35.47, p<.001$, with a Nagelkerke's $\mathrm{R}^{2}$ of .21 and a Hosmer and Lemeshow's $\chi^{2}$ of 5.23, $p=.73$. Both personal stereotypes $(\beta=.02, \exp =1.02, p<0.05)$ and causal attributions $(\beta=-.11, \exp =.90, p<$ .001) emerged as significant predictors of DOM verdicts. Specifically, mock jurors who held negative stereotypes about the defendant's racial group were 1.02 times more likely to find that defendant guilty of DOM. With regards to attributions, mock jurors who made internal, as opposed to external, attributions about the cause of the crime were .90 times more likely to convict the defendant of DOM. The results from the logistic regression are presented in Table 2. 
RACE IN THE CANADIAN COURTROOM

Table 2. Summary of Logistic Regression Analysis for the DOM Charge Predicting

Dichotomous Verdict $(N=210)$

\begin{tabular}{ccccccc}
\hline Variable & B & SE & OR & $95 \%$ CI & $\begin{array}{c}\text { Wald } \\
\text { Statistic }\end{array}$ & $p$ \\
\hline Defendant Race & & & & & \\
White & & & & & & \\
Black & .71 & .52 & 2.03 & {$[.74,5.61]$} & 1.87 & .17 \\
Aboriginal & .26 & .51 & 1.29 & {$[.48,3.55]$} & .26 & .61 \\
Type of Article & & & & & & \\
Race Neutral & & & & & & .35 \\
General Race & -.37 & .40 & .69 & {$[.31,1.51]$} & .86 & .02 \\
Race Specific & -.11 & .4 & .89 & {$[.41,1.97]$} & .07 & .79 \\
Personal Stereotypes & .02 & .01 & 1.02 & {$[1.00,1.03]$} & 5.40 & .02 \\
Causal Attributions & -.11 & 1.57 & .90 & {$[.86, .93]$} & 21.93 & .00 \\
\hline
\end{tabular}

Note. $\mathrm{CI}=$ Confidence interval for odds ratio (OR). $\mathrm{SE}=$ Standard Error.

${ }^{a}$ Reference category (coded as 0 ) for all predictor variables.

*This parameter is set to zero because it is redundant

Similar trends were observed for the impaired driving charge. A test of the full model against a constant-only model generated significant findings, $\chi^{2}=41.47, p<.001$, with a Nagelkerke's $\mathrm{R}^{2}$ of .23 and a Hosmer and Lemeshow's $\chi^{2}$ of 5.76, $p=.67$.

Personal stereotypes $(\beta=.04, \exp =1.04, p<0.001)$ as well as causal attribution judgements $(\beta=-.08, \exp =.92, p<.001)$ were found to be significant predictors of verdict for the impaired driving charge. Overall, negative stereotypes towards the defendant's racial group appeared to make mock jurors 1.04 times more likely to convict him of impaired driving. Likewise, mock jurors who ascribed the crime to factors internal to the defendant were .92 times more likely to convict him. The results from the logistic regression are presented in Table 3. 
RACE IN THE CANADIAN COURTROOM

Table 3. Summary of Logistic Regression Analysis for the Impaired Driving Charge

Predicting Dichotomous Verdict $(N=210)$

\begin{tabular}{|c|c|c|c|c|c|c|}
\hline Variable & B & SE & OR & $95 \% \mathrm{CI}$ & $\begin{array}{c}\text { Wald } \\
\text { Statistic }\end{array}$ & $p$ \\
\hline \multicolumn{7}{|l|}{ Defendant Race } \\
\hline White $^{\mathrm{a}}$ & $0^{*}$ & & & & & \\
\hline Black & .10 & .53 & 1.10 & {$[.38,3.16]$} & .03 & .86 \\
\hline Aboriginal & -.02 & .54 & .98 & {$[.34,2.83]$} & .00 & .97 \\
\hline \multicolumn{7}{|l|}{ Type of Article } \\
\hline Race Neutral ${ }^{\mathrm{a}}$ & $0^{*}$ & & & & & \\
\hline General Race & -.44 & .43 & .64 & {$[.67,3.62]$} & 1.07 & .30 \\
\hline Race Specific & .56 & .43 & 1.75 & {$[.76,4.04]$} & 1.72 & .19 \\
\hline Personal Stereotypes & .04 & .01 & 1.04 & {$[1.02,1.06]$} & 17.29 & .00 \\
\hline Causal Attributions & -.08 & 1.36 & .92 & {$[.89, .96]$} & 17.95 & .00 \\
\hline
\end{tabular}

Note. $\mathrm{CI}=$ Confidence interval for odds ratio (OR). $\mathrm{SE}=$ Standard Error.

${ }^{a}$ Reference category (coded as 0 ) for all predictor variables.

*This parameter is set to zero because it is redundant

\section{Continuous Analyses}

Hypothesis 2 predicted that there would be a relationship between defendant race and trial decisions, such that Black and Aboriginal-Canadian defendants would be found guilty with more certainty and given harsher sentences than White defendants.

Hypothesis 2 a predicted that the relationship between defendant race and trial decisions would be reduced or eliminated in conditions where participants had been exposed to racially charged media. This effect was predicted to be true for both the race specific and general race conditions, given that both articles feature prominent racial overtones but was predicted to be strongest for mock jurors presented with the race specific article as it 
exclusively related to the race of the defendant. A depiction of mock jurors' trial decisions by defendant race are displayed in Table 4 .

Table 4. Descriptive Statistics by Defendant Race

\begin{tabular}{cccccccc}
\hline $\begin{array}{c}\text { Defendant } \\
\text { Race }\end{array}$ & $\begin{array}{c}\text { DOM } \\
\text { Verdict } \\
\text { Confidence }\end{array}$ & $\begin{array}{c}\text { Impaired } \\
\text { Verdict } \\
\text { Confidence }\end{array}$ & $\begin{array}{c}\text { DOM } \\
\text { Sentence }\end{array}$ & $\begin{array}{c}\text { Impaired } \\
\text { Sentence }\end{array}$ & $\begin{array}{c}\text { Personal } \\
\text { Stereotypes }\end{array}$ & $\begin{array}{c}\text { Cultural } \\
\text { Stereotypes }\end{array}$ & $\begin{array}{c}\text { Causal } \\
\text { Attributions }\end{array}$ \\
\hline \multirow{2}{*}{ White } & $M=.50$ & $M=-1.70$ & $M=5.39$ & $M=4.88$ & $M=69.10$ & $M=64.43$ & $M=4.96$ \\
& $S D=8.46$ & $S D=8.00$ & $S D=2.75$ & $S D=2.47$ & $S D=15.73$ & $S D=15.08$ & $S D=2.37$ \\
Black & $M=1.30$ & $M=-1.06$ & $M=6.02$ & $M=4.69$ & $M=61.88$ & $M=83.79$ & $M=5.30$ \\
& $S D=7.82$ & $S D=7.74$ & $S D=2.43$ & $S D=2.34$ & $S D=19.27$ & $S D=18.97$ & $S D=2.38$ \\
Aboriginal & $M=-.17$ & $M=-2.00$ & $M=5.10$ & $M=4.68$ & $M=60.92$ & $M=85.64$ & $M=5.44$ \\
& $S D=8.06$ & $S D=7.63$ & $S D=2.32$ & $S D=2.79$ & $S D=21.59$ & $S D=21.40$ & $S D=2.18$ \\
& & & & & & & \\
\hline
\end{tabular}

In order to test these hypotheses, a series of planned comparisons were conducted (see Table 5). First, a comparison between the White/Racially Neutral (i.e., control) condition and the Minority/Racially Neutral conditions (i.e., Black/Race Neutral, Aboriginal/Race Neutral) were evaluated to determine if verdicts, sentencing, or causal attributions differed as a function of defendant race. Second, to determine whether trial decisions varied as a function of racially charged media, a comparison between the Racially Neutral (i.e., Black/Race Neutral, Aboriginal/Race Neutral) conditions and the Racially Charged (i.e., Black/General Race, Aboriginal/General Race, Black/Race Specific, Aboriginal/Race Specific) conditions was conducted. Finally, a comparison of the Race-Specific (Black/Race Specific, Aboriginal/Race Specific) and General Race (Black/General Race, Aboriginal/General Race) conditions was conducted to assess whether the specificity of the racial overtones influenced verdicts, sentencing, or causal attributions.

Table 5. Planned Contrast Weights 


\begin{tabular}{|c|c|c|c|c|c|c|c|}
\hline \multirow[b]{2}{*}{ Contrasts } & \multicolumn{7}{|c|}{ Conditions } \\
\hline & $\begin{array}{l}\text { White/ } \\
\text { Race } \\
\text { Neutral }\end{array}$ & $\begin{array}{l}\text { Black/ } \\
\text { Race } \\
\text { Neutral }\end{array}$ & $\begin{array}{c}\text { Aboriginal/ } \\
\text { Race } \\
\text { Neutral }\end{array}$ & $\begin{array}{c}\text { Black } \\
\text { General } \\
\text { Race }\end{array}$ & $\begin{array}{c}\text { Aboriginal/ } \\
\text { General } \\
\text { Race }\end{array}$ & $\begin{array}{l}\text { Black/ } \\
\text { Race } \\
\text { Specific }\end{array}$ & $\begin{array}{c}\text { Aboriginal } \\
\text { Race } \\
\text { Specific }\end{array}$ \\
\hline 1 & 2 & -1 & -1 & 0 & 0 & 0 & 0 \\
\hline 2 & 0 & 2 & 2 & -1 & -1 & -1 & -1 \\
\hline 3 & 0 & 0 & 0 & 1 & 1 & -1 & -1 \\
\hline
\end{tabular}

Verdict certainty. Contrary to prediction, mock jurors' guilt certainty ratings did not differ as a function of defendant race $(\mathrm{DOM}, t(203)=-.38, p=.69$; impaired driving, $t(52.51)=5.00, p=.62)$. For the DOM charge, neither the type of article presented, $t(203)=.73, p=.47$, nor the racial specificity of the article, $t(203)=-.32, p=.74$, affected mock jurors' guilt certainty ratings. The same was true for the impaired driving charge. There was no effect of article type, $t(127.08)=-1.332, p=.18$, nor article specificity, $t(115.71)=-.09, p=.93$, on mock jurors' guilt certainty ratings.

Sentence length. Mock jurors' sentence recommendations were unaffected by defendant race $(\mathrm{DOM}, t(125)=.97, p=.33$; impaired driving, $t(100)=1.09, p=.28)$. However, results revealed a significant effect of type of article on sentence length for the DOM charge, $t(125)=-2.25, p<.01$, such that mock jurors sentenced racialized defendants more harshly when they were presented with a race salient article $(M=5.79$, $S D=2.25)$ compared to a non-race salient article $(M=4.76, S D=1.95)$. The effect of article type on racialized defendants' sentence length for the DOM charge is displayed in Figure 1. A significant effect of article specificity was also found to influence mock jurors' sentence recommendations for the DOM charge, $t(125)=-2.30, p<.01$. More specifically, mock jurors were more punitive towards racialized defendants after reading the race specific articles $(M=6.40, S D=2.21)$ compared to the general race articles $(M$ $=5.18, S D=2.30)$. The effect of article specificity on racialized defendants' sentence length for the DOM charge is displayed in Figure 2. 
Causal attributions. With regards to mock jurors attributions about the cause of the crime, neither defendant race, $t(203)=.31, p=.75$, nor type of article, $t(203)=-1.81$, $p=.24$, nor article specificity, $t(203)=.32, p=.75$, influenced mock jurors' causal attributions.

Personal stereotypes. Results revealed that mock jurors' personal stereotypes differed as a function of defendant race, $t(203)=2.20, p<.01$. Contrary to prediction, mock jurors appeared to hold more positive views of Black and Aboriginal-Canadians ( $M$ $=59.32, S D=19.68)$ compared to White individuals $(M=69.10, S D=15.73)$. To tease apart this effect, an independent t-test was conducted. Overall, there was no significant difference between mock jurors' impressions of Black and Aboriginal-Canadians, $t(178)$ $=.31, p=.75$. Expectedly, the type of article, $t(203)=-.99, p=.32$, and article specificity, $t(203)=.89, p=.37$, did not have an effect on mock jurors' personal racial stereotypes.

Cultural stereotypes. Results also revealed that defendant race had a significant effect on mock jurors' perceived cultural stereotypes, $t(203)=-4.01, p<.001$. Overall, mock jurors suggested that White defendants $(M=64.43, S D=15.08)$ were viewed more positively by society compared to Black and Aboriginal-Canadians $(M=81.83, S D=$ 19.33). A separate independent t-test suggested that mock jurors perceived Black and Aboriginal-Canadians to be viewed similarly, $t(178)=-.62, p=.54$. Neither the type of article, $t(203)=-1.36, p=.18$, nor article specificity, $t(203)=-1.11, p=.30$, influenced mock jurors' perceived cultural stereotypes.

Symbolic racism. To determine whether there was a relationship between symbolic racism and verdicts, correlational analyses were performed. For both the Black 
and Aboriginal-Canadian defendant, racial animosity was associated with guilty verdicts for the DOM (Black, $r=.34, p<.001$; Aboriginal, $r=.23, p<.01$ ) and impaired driving charge (Black, $r=.30, p<.001$; Aboriginal, $r=.37, p<.001$ ). To examine whether mock jurors' symbolic racism scores differed as a function of defendant race or article type, a 2 (Defendant race: Black, Aboriginal-Canadian), x 3 (Type of article: Neutral, General, Specific) analysis of variance was conducted. Findings revealed a marginally significant interaction between defendant race and type of article, $F(1,174)=2.73, p<.10, \eta^{2}=$ .03. Simple effects demonstrated that mock jurors scored marginally higher on the symbolic racism scale when presented with a general race article $(M=22.9)$, as compared to a race specific $(M=21.53)$ or race neutral $(M=20.57)$ article when the defendant was Aboriginal, $F(2,87)=2.6, p<.10, \eta^{2}=.06$. There was no effect of article type for the Black defendant. There were no main effects of defendant race $F(1,174)=.27, p=.61$, $\eta^{2}=.00$, or type of article, $F(2,174)=.54, p=.58, \eta^{2}=.00$.

\section{Discussion}

The purpose of the present study was to determine, using a mock-jury paradigm, whether potential jurors would discriminate against a criminal defendant of AboriginalCanadian or Black descent and whether being exposed to racially charged media would have any bearing on their decisions. We hypothesized that this study would replicate earlier research demonstrating a relationship between defendant race and trial decisions, such that Black and Aboriginal-Canadians would receive harsher verdicts and longer sentences (e.g., Mitchell et al., 2005; Pfeifer \& Ogloff, 2003). Based on the aversive racism theory, we also predicted that this relationship would be reduced or eliminated when participants had been exposed to racially charged media, as the racial overtones 
were expected to remind jurors of their desire to be or appear unprejudiced (e.g., Sommers \& Ellsworth, 2001). These hypotheses were not supported.

Overall, mock jurors who endorsed negative stereotypes about the defendant's racial group were more likely to find the defendant guilty of both the DOM and impaired driving charge. Contrary to previous research, verdict judgements, sentencing decisions, and causal attributions did not differ as a function of defendant race. Interestingly, however, the type of article that jurors read had bearing on mock jurors' sentencing decisions. More specifically, mock jurors were more punitive towards a racialized defendant after reading a race salient article that specifically alluded to the defendant's race compared to an article that discussed race more generally or the non-race salient article.

There are several possible explanations for these findings. In previous studies investigating race salience, researchers have found that making race salient reduces White juror bias towards Black defendants (e.g., Sommers \& Ellsworth, 2000; 2001). That is, when jurors are reminded that their decision could appear prejudicial, they are more motivated to respond in a socially desirable manner. However, making race salient is not said to have a similar impact on all juror decision-making (Sommers, 2009). In the current study, race was made salient through exposing mock jurors to racially charged media and was not central to the defendant's case. Findings from Sommers, Warp, and Mahoney (2008) suggest that making race salient heightens the accessibility of racerelated thoughts. This increase in cognitive accessibility may have cued implicit racial attitudes and primed jurors who read the race salient articles to overemphasize issues of race, leading prejudiced jurors to sentence the Black and Aboriginal-Canadian defendants 
more harshly. These findings lend support to the theory of aversive racism, which posits that individuals will almost always make the socially acceptable decision when there are clear guidelines present, as is the case in verdict judgements, but are more likely to display bias in ambiguous circumstances, such as sentencing decisions (Gaertner \& Dovidio, 1986; Mitchell et al., 2005; Pfeifer \& Ogloff, 2003).

This premise is further supported by mock jurors' stereotypic judgements. Not surprisingly, mock jurors perceived culturally held stereotypes about Black and Aboriginal-Canadians to be more negative than personally held beliefs. Consistent with the aversive racism theory, these findings may reflect egalitarian self-concepts coexisting with the ostensible peril of appearing prejudiced (Gaertner \& Dovidio, 1986; Katz \& Braly, 1993). On the basis of agenda-setting, we suspect that this may also explain the null findings with regards to causal attributions, as Gaertner and Dovidio (1986) have noted that White jurors are less likely to demonstrate racial bias when concerns about prejudice are salient (McCombs \& Shaw, 1972). While past research has demonstrated that prejudiced individuals are more likely to make internal attributions for a defendant's criminal behaviour (e.g., Gordon, 1990), this study diverged from previous findings. Surprisingly, mock jurors' causal attributions were only moderately related to personally held racial stereotypes. Since the questions assessing mock jurors' attributions were relatively unambiguous, it is possible that they may have prompted socially desirable responses, resulting in more external causal attributions and lower responsibility ratings than would have otherwise been dispensed.

A potentially more troubling finding is the interaction between defendant race and type of article on mock jurors' symbolic racism scores. Overall, the general race article 
appeared to activate racial biases towards Aboriginal-Canadians. That is, when mock jurors were presented with the general race article followed by a trial transcript involving an Aboriginal-Canadian defendant, they scored higher on the symbolic racism measure. These findings may reflect the racial tension between Whites and Aboriginal-Canadians in Canada. The history of Aboriginals-Canadians in Canada is fraught with discriminatory policies and endemic abuses, such as residential schools that were established to eliminate Aboriginal culture (Aboriginal Affairs, 2013). Over the years, the marginalization of Aboriginal-Canadians in Canada gained greater awareness, and the notion that Aboriginal equality could only be achieved by the loss of Aboriginal identity was abandoned. More recent attempts to address the injustices of the past have resulted in unique and distinctive policies that recognize and affirm Aboriginal-Canadian rights. Thus, despite Canada's more recent efforts to move towards cultural pluralism, prior race relations between Canada and Aboriginal-Canadians remain distinguishing historical features (Vickers, 2002).

Furthermore, the article framed the need for cultural competence in the healthcare field in a socially relevant manner. Being that culture, heritage, and language are the cornerstones of Aboriginal-Canadian communities, it is possible that the article was more pertinent for the defendant of Aboriginal descent. Accordingly, the general race article may have primed higher symbolic racism scores for the Aboriginal-Canadian defendant, perhaps reflecting Canadian mock jurors' animosity towards the special protections in place to preserve Aboriginal-Canadian culture in comparison to the lack of considerations afforded to other racialized groups in Canada (Cairns, 2003). In following, the Aboriginal 
race specific article may have alerted mock jurors as to the purpose of the study, causing mock jurors to inevitably change their reported attitudes towards Aboriginal-Canadians.

Taken collectively, the results of the present study illustrate the complex relationship between racial attitudes and juror decision-making. While our study did not find verdict judgements to differ as a function of defendant race, our study demonstrated that when race is not a central feature to the case, making race salient may actually increase levels of racial bias for some mock jurors. The implication of this research largely appears to be that race salience affects Canadian and American mock jurors differently. More specifically, rather than reducing White juror bias against Black defendants, making race salient in Canada may in fact be detrimental to a racialized defendant's case. An explanation for this disparity may rest in the distinction that can be made between the two countries with regards to prior race relations (Statistics Canada, 2008; U.S. Department of Commerce, 2012; Vickers, 2002). The effects of race salience found in the literature are founded on the aversive racism framework, which is a result of the central role Black exploitation has played in the history of the United States (Sommers, 2007). Race relations between White and Aboriginal-Canadians, however, have been characterized by years of subordination and oppression, with far less political and social awareness (Centre for Social Justice, 2014). In comparison to Black history in the United States, research suggests that Canadians are far less informed about the marginalization of Aboriginal-Canadians. For instance, the Urban Aboriginal Peoples' Survey (2010) reported that the majority of the non-Aboriginals surveyed across Canada had never heard or read anything about residential schools, and perceived AboriginalCanadians to be well off in comparison to other Canadians. Thus, there appears to be a 
significant gap between the triumphs and tragedies experienced by Aboriginal-Canadians and the knowledge of non-Aboriginal Canadians. The social norms pertaining to discrimination against Black individuals appear to be less ambiguous than the appropriate attitudes and behaviours concerning Aboriginal-Canadians. Given these differences, it is possible that the effects of race salience in Canada may be negated or reversed for mock jurors as a function of social ignorance. If Canadian mock jurors are less socially aware that their attitudes and behaviour deviate from societal norms, they may be less motivated to try and appear egalitarian.

\section{Limitations and Future Directions}

The findings from this study should be interpreted in light of several limitations. First, the current study used racially charged news articles to increase the cognitive accessibility of racial issues in the community. The race salience manipulations in these news articles were more explicit than previous manipulations of race salience; therefore, it is possible that these manipulations were too strong and reactive given the sensitivity of the subject matter. Previous (more subtle) forms of race salience manipulations have included asking prospective jurors racially relevant voir dire questioning or framing the crime in racially charged terms (e.g., Bucolo \& Cohn, 2010; Sommers, 2006). In an effort to make race accessible, the current study's general race and race specific articles may have cued participants as to the research question. In order to avoid this ambiguity, future research should assess participants' reactions to the strength of race salience manipulation through pilot testing.

Second, within the trial transcripts, only one photo was used to depict each racial category. While these photos were matched on perceived likability, age, and 
attractiveness, research on racial appearance suggests that the more stereotypically Black (or Aboriginal) a defendant appears, the more likely he is to experience racial bias (Eberhardt, Davies, Purdie-Vaughns \& Johnson, 1996). Thus, it is possible that the photographs differed in the degree to which they were stereotypically depictive of their racial groups.

Additionally, the present study focused on individual juror judgements and thus, direct comparison of these findings to group level data is cautioned. While jurors' independent responses are important to study the effects of race, trial outcomes inevitably depend on group decisions. Attaining a unanimous verdict requires more complex processes of decision making, which may enhance or disguise individual juror bias. For instance, Bothwell, Pigott, Foley, and McFatter (2006) found that group deliberation helped to reduce racial bias against the defendant. However, other research has shown that the deliberation process can augment racial biases (Bernard, 1979). Furthermore, the deliberation literature suggests that the racial composition of a jury can significantly affect final verdict decisions (Kerr, Hymes, Anderson \& Weathers, 1995; Perez, Hosch, Ponder \& Trejo, 1993; Sommers, 2006). Nevertheless, findings from Kalven and Zeisel (1966) suggest that individual predeliberation decisions are often the best predictors of deliberated verdicts. Therefore, assessing individual judgements may provide the best insight as to the process through which race is likely to influence juror judgements. The current study also differed from a real trial process in that mock jurors were not burdened with the responsibility and consequences of their decisions, as it is difficult to emulate the social psychological stressors of actual verdict decisions (Costanzo \& Costanzo, 1992). 
Finally, the generalizability of the findings in the present study may be limited as mock jurors were presented with a written trial transcript and questionnaire that were competed online, which differs significantly in comparison to a real trial process. The fact that mock jurors read only a brief transcript leads to the possibility that some mock jurors may have relied more heavily on specific evidentiary or non-evidentiary factors than they would have otherwise, had they been exposed to the complete trial process. Nonetheless, research assessing the effects of modality on juror decision making has found that the medium by which trial information is presented has little effect on the quality or nature of the data being collected (Bornstein, 1999; Pezdek, Avila-Mora, \& Sperry, 2010). The use of web-based studies has also shown to be comparable, if not more representative, to that of in-lab research and thus should not undermine the external validity of this study (Birnbaum, 2000; Buchanan \& Smith, 1999; Krantz \& Reeshad, 2000; Riva, Teruzzi, \& Anolli, 2003).

To overcome these limitations, future research should investigate the influence of race salience at the group level, and assess the process by which deliberations may be influenced by race salience. Future research should also seek to incorporate both implicit and explicit measures of racial bias, as research suggests that explicit and implicit biases often diverge (Dovidio, Kawakami \& Gaertner, 2002). While the findings by Cohn, Bucolo, Pride and Sommers (2009) suggest that both high and low prejudiced jurors are influenced by race salience manipulations, our study failed to find an association between racial bias and verdict judgements using principally explicit measures.

Future efforts should also use other types of race salience manipulations to determine in which circumstances Black and Aboriginal-Canadian defendants can benefit 
from making racial attitudes more accessible during a trial. For instance, it would be interesting to see whether highlighting race through positive pre-trial publicity or a character witness would have an effect on trial judgements, and whether this strategy would benefit Black and Aboriginal-Canadians equally. Similarly, to date, studies of race salience have generally looked at its effect with regards to charges of assault or manslaughter. Subsequent research should investigate the other types of crimes (e.g., armed robbery), or victimless crimes (e.g., possession or use of illicit drugs) to determine the pervasiveness of this effect (Gordon, 1990).

Although future research is needed, the findings from the current study provide some evidence that making race salient may in fact be detrimental to a racialized defendant's case in Canada. Collectively, these findings in conjunction with the race salience literature contribute to advancements in the development of mechanisms and procedures to ensure that all racialized defendants receive a fair trial, as they indicate that making race salient prior to the trial may not be a viable solution to improve impartiality. From a legal perspective, the findings from this study also provide additional evidence to the notion that, similar to the United States, race may play a role in jury decision making in Canada. Further research will have important implications for the alleged double standard facing racialized defendants, and should focus on extending current literature by examining whether race salience would have the same effect on other Canadian minority members.

\section{References}


Aboriginal Affairs and Northern Development Canada (2013). History of First Nations Newcomer Relations. Retrieved from https://www.aadnc-aandc.gc.ca/eng/130 $7460755710 / 1307460872523$

Aboriginal Justice Inquiry (1999). Aboriginal Justice Implementation Commission.

Retrieved from http://www.ajic.mb.ca/volume.html

Bagby, R. M., Parker, J. D., Rector, N. A., \& Kalemba, V. (1994). Racial prejudice in the Canadian legal system. Law and Human Behavior, 18(3), 339-350.

doi:10.1007/BF01499592

Bernard, J. L. (1979). Interaction between the race of the defendant and that of jurors in determining verdicts. Law and Psychology Reviews, 5, 103-111. Retrieved from http://heinonline.org/HOL/LandingPage?handle=hein.journals/lpsyr5\&div=8\&id= \&page

Birnbaum, M.H. (Ed.). (2000). Psychological experiments on the Internet. San Diego: Academic Press.

Bornstein, B.H. (1999). The ecological validity of jury simulations: Is the jury still out? Law and Human Behaviour, 23(1), 75-91.

Bothwell, R. K., Pigott, M. A., Foley, L. A., \& McFatter, R. M., (2006). Racial bias in juridic judgement at private and public levels, Journal of Applied Social Psychology, 36(9). doi:10.1111/j.0021-9029.2006.00098.x

Buchanan, T., \& Smith, J.L. (1999). Using the Internet for psychological research: Personality testing on the World-Wide Web. British Journal of Psychology, 90, 125-144. doi: 10.1348/000712699161189 
Bucolo, D. O., \& Cohn, E. S. (2010). Playing the race card: Making race salient in defence opening and closing statements. Legal and Criminological Psychology, 15(2), 293-303. doi:10.1348/135532508X400824

Cairns, A. (2003). Afterword: International dimensions of the citizen issue of indigenous peoples/nations. Citizenship Studies, 7(4). doi:10.1080/1362102032000135001

Canadian Multiculturalism: An Inclusive Citizenship. Report from the Government of Canada. Retrieved from http://www.cic.gc.ca/english/multiculturalism/citiz enship.asp

Centre for Social Justice (2014). Aboriginal Issues. Retrieved from http://www.social justice.org/index.php?page=aboriginal-issues

Cohn, E. S., Bucolo, D. O., Pride, M., Sommers, S. R. (2009). Reducing white juror bias: The role of race salience and racial attitudes. Journal of Applied Social Psychology, 39(8), 1953-1973. doi: 10.1111/jasp.2009.39.issue-8

Cohen, J., Cohen, P., West, S., \& Aiken, L. (2003). Applied Multiple Regression/Correlation Analysis for the Behavioural Science. Mahwah, NJ: Lawrence Erlbaum Associates

Corenblum, B., \& Stephan, W. G. (2001). White fears and Native apprehensions: An integrated threat theory approach to intergroup attitudes. Canadian Journal of Behavioural Science, 33(4), 251-268. doi: 10.1037/h0087147.

Correll, J., Park, B., Judd, C. M., \& Wittenbrink, B. (2002). The police officer's dilemma: Using ethnicity to disambiguate potentially threatening individuals. Journal of Personality and Social Psychology, 83(6), 1314-1329. doi:10.1037//00223514.83 .6 .1314 
Correll, J., Park, B., Judd, C. M., \& Wittenbrink, B. (2007). The influence of stereotypes on decisions to shoot. European Journal of Social Psychology, 37, 102-117. doi: $10.1002 /$ ejsp. 450

Costanzo, M., \& Costanzo, S. (1992). Jury decision making in the capital punishment phase: Legal assumptions, empirical findings, and a research agenda. Law and Human Behavior, 16, 185-201. doi: 10.1007/BF01044797

Devin, P. G., \& Elliot, A. J. (1995). Are racial stereotypes really fading? The Princeton Trilogy revisited. Personality and Social Psychology Bulletin, 21(11), 1139-1150. doi:10.1177/01461672952111002

Dovidio, J. F., \& Gaertner, S. L. (1996). Affirmative action, unintentional racial biases, and intergroup relations. Journal of Social Issues, 52(4), 51-75. doi:10.1111/j.1540-4560.1996.tb01848.x

Dovidio, J. F., \& Gaertner, S. L. (2000). Aversive racism and selection decisions: 1989 and 1999. Psychological Science, 11(4), 315-319. doi:10.1016/S0065-2601

Dovidio, J. F., Kawakami, K., \& Gaertner, S. L. (2002). Implicit and explicit prejudice and interracial interaction. Journal of Personality and Social Psychology, 82(1), 62-68. doi: 10.1037//0022-3514.82.1.62

Dovidio, J. F., Smith, J. K., Donnella, A. G., \& Gaertner, S. L. (1997). Racial attitudes and the death penalty. Journal of Applied Social Psychology, 27, 1468-1487. doi: 10.111/j.1559-1816.1997.tb01609.x

Eberhardt, J. L., Davies, P. G., Purdie-Vaughns, V. J., \& Johnson, S. L. (2006). Perceived stereotypicality of Black defendants predicts capital-sentencing outcomes. Psychological Science, 17(5), 383-386. doi:10.1111/j.1467-9280.2006.01716.x 
Eberhardt, J. L., Goff, P. A., Purdie, V. J., \& Davies, P. G. (2004). Seeing black: Race, crime and visual processing. Journal of Personality and Social Psychology, 87(6), 876-893. doi:10.103/0022-3514.87.6.876

Erber, R., \& Fiske, S. T. (1984). Outcome dependency and attention to inconsistent information. Journal of Personality and Social Psychology, 47(4), 709-726. doi:10.1037/0022-3514.47.4.709

Fein, S., Morgan, S. J., Norton, M. I., \& Sommers, S. R. (1997). Hype and suspicion: The effects of pretrial publicity, race, and suspicion on jurors' verdicts. Journal of Social Issues, 53(3), 487-502. doi: 10.1111/j.540-4560.1997.tb02124.x

Fiske, S. (1998). Stereotyping, prejudice, and discrimination. In D. Gilbert, S. Fiske, \& G. Lindzey (Eds.), The handbook of social psychology (pp.357-411). New York, NY: McGraw-Hill.

Flemming, W. (2006). Myths and stereotypes about Native Americans. Retrieved from http://www.jcu.edu/education/ed350/Myths\%20and\%20Stereotypes\%20 About $\% 20$ Native $\% 20$ Americans.pdf

Gaertner, S. L., \& Dovidio, J. F. (1986). The aversive form of racism. In J.Dovidio, \& S. Gaertner (Eds.), Prejudice, discrimination and racism (pp.61-89). Toronto: Academic Press.

Gaertner, S. L., \& Dovidio, J. F. (2005). Understand and addressing contemporary racism: From aversive racism to the common in-group identity model. Journal of Social Issues, 61(3), 615-639. doi:10.1111/j.1540-4560.2005.0024.x 
Gordon, R. A. (1990). Attributions for blue-collar and white-collar crime: The effects of subjects and defendant race on simulated juror decisions. Journal of Applied Social Psychology, 20(12), 971-983. doi:10.1111/j.1559-1816.1990.tb00385.x

Henry, P. J., \& Sears D. O. (2002). The Symbolic Racism 2000 Scale. Political Psychology, 23(2), 253-283.

Higgins, P. L., Heath, W. P., \& Grannemann, B. D. (2007). How type of excuse defense, mock juror age, and defendant age affect mock juror' decisions. Journal of Social Psychology, 147(4), 371-392. Retrieved from http://www.ncbi.nlm.nih. gov/pubmed/17955749

Hodson, G., Dovidio, J. F., \& Gaertner, S. L. (2002). Processes in racial discrimination: Differential weighting of conflicting information. Personality and Social Psychology Bulletin, 28(4), 460-471. doi:10.1177/0146167202287004

Huizinga, D., Tornberry, T., Knight, K., \& Lovegrove, P. (2007). Disproportionate minority contact in the juvenile justice system: A study of differential minority arrest/referral to court in three cities. Washington, DC: U.S Department of Justice.

Iyengar, S., Kinder, D. R. (1985). Psychological accounts of agenda setting. In S. Kraus \& R. Perloff (Eds), Mass media and political thought. Beverly Hills, CA: Sage.

Jones, C. S., \& Kaplan, M. F. (2003). The effects of racially stereotypical crimes on juror decision-making and information-processing strategies. Basic and Applied Social Psychology, 25(1), 1-13. doi: 10.1207/S15324834BASP2501_1

Kalven, H., \& Zeisel, H. (1966). The American Jury. Chicago: University of Chicago Press. 
Katz, D., \& Braly, K. (1993). Racial stereotypes of one hundred college students. Journal of Abnormal and Social Psychology, 28(3), 280-290. doi:10.1037/h0074049

Kerr, N. L., Hymes, R. W., Anderson, A. B., \& Weathers, J. E. (1995). Defendant-juror similarity and mock juror judgments. Law and Human Behavior, 19(6). doi: 10.1007/BF01499374

Kovera, M. B. (2002). The effects of general pretrial publicity on juror decisions: An examination of moderators and mediating mechanisms. Law and Human Behavior, 26(1), 43-71. doi: 10.1023/A:1013829224920

Krantz, J.H. \& Reeshad, D. (2000). Validity of web-based psychological research. Psychological Experiments on the Internet. Birnbaum, M.H. (ed.), Academic Press: San Diego.

Krueger, J. (1996). Personal beliefs and cultural stereotypes about racial characteristics. Journal of Personality and Social Psychology, 71(3), 536-548. doi:10.1037/00223514.71 .3 .536

Kutner, M., Nachtsheim, C., Neter, J., \& Li. W. (2004). Applied Linear Statistics Model. Chicago.

Lynch, M. \& Haney, C. (2011). Mapping the racial bias of the White male capital juror: Jury composition and the "empathic divide". Law \& Society Review, 45, 69-102. doi: $10.1111 / \mathrm{j} .1540-5893.2011 .00428 . x$

Macrae, N. C., Hewstone, M., \& Griffiths, R. J. (1993). Processing load and memory for stereotyped-based information. European Journal of Social Psychology, 23(1), 77-87. doi:10.1002/ejsp.242023107 
Maeder, E. M., \& Burdett, J. (2013). The combined effect of defendant race and alleged gang affiliation on mock juror decision-making. Psychiatry, Psychology and Law, 20(2), 1-14. doi:10.1080/13218719.2011.633330

Mazzella, R., \& Feingold, A. (1994). The effects of physical attractiveness, race, socioeconomic status, and gender of defendants and victims on judgments of mock jurors: A meta-analysis. Journal of Applied Social Psychology, 24(15), 1315-1338. doi:10.111/j.1559-1816.1994.tb01552.x.

McCombs, M, E., Shaw, D. (1972). The agenda-setting function of mass media. Public Opinion Quarterly, 36(2), 2098-2109. doi: 10.1086/267990

McGuire, M. V., \& Bermant, G. (1977). Individual and group decisions in response to a mock trial: A methodological note. Journal of Applied Social Psychology, 7(3), 220-226. doi: 10.1111/j.1559-1816

Mitchell, T. L., Haw, R. M., Pfeifer, J. E., \& Meissner, C. A. (2005). Racial bias in mock juror decision-making: A meta-analytic review of defendant treatment. Law and Human Behavior, 29(6), 621-637. doi:10.1007/s10979-005-8122-9

Office of the Correctional Investigator (2013). Annual Report from the Government of Canada. Retrieved from http://www.oci-bec.gc.ca/rpt/pdf/annrpt/annrpt20112012eng.pdf

Perez, D. A., Hosch, H. M., Ponder, B., \& Trejo, G. C. (1993). Ethnicity of defendants and jurors as influences on jury decisions. Journal of Applied Social Psychology, 23, 1249-1262. doi: 10.1111/j.1559-1816.1993.tb01031.x 
Pezdek, K. Avila-Mora, E., \& Sperry, K. (2010). Does trial presentation medium matter in jury simulation research? Evaluating the effectiveness of eyewitness expert testimony. Applied Cognitive Psychology, 24(5), 673-690. doi: 10.1002/acp.1578

Pfeifer, J. E., \& Ogloff, J. R. (2003). Mock juror's ratings of guilt in Canada: Modern racism and ethnic heritage. Social Behavior and Personality, 31(3), 301-312. doi:10.2224/sbp.2003.31.3.301

Public Safety Canada (2012). Corrections and Conditional Release Statistical Overview. Retrieved from http://www.publicsafety.gc.ca/cnt/rsrcs/pblctns/2012-ccrs/indexeng.aspx

Riva, G., Teruzzi, T., \& Anolli, L. (2003). The use of the internet in psychological research: Comparison of online and offline questionnaires. Cyberpscyhological Behavior, 6(1). 73-80.

Rehavi, M., \& Starr, S. (2012). Racial disparity in federal criminal charging and its sentencing consequences. University of Michigan Law \& Economics, Empirical Legal Studies Center Paper No. 12-002.

Roberts, J. V., \& Melchers, R. (2003). Incarceration of Aboriginal Offenders: Trends from 1978 to 2001. Canadian Journal of Criminology and Criminal Justice, 45(2), 211-242.

R. v. Collins (2011). O.J. No. 978.

R. v. Gladue (1999). 1 S.C.R. 688.

R. v. Jensen (2005). 74 O.R. (3d) 561.

R. v. Kootenay (2006). A.J. No. 439.

R. v. Parks (1993). O.J. No. 2157. 
R. v. Thomas (2005). M.J. No. 161.

R. v. Wells (2000). 1 S.C.R. 207.

R. v. Williams (1998). 1 S.C.R. 1128.

Sampson, R. J., \& Lauritsen, J. L. (1997). Racial and ethnic disparities in crime and criminal justice in the United States. Crime and Justice, 21, 311-374. Retrieved from http://www.jstor.org/stable/1147634

Schneider, D. (2004). The psychology of stereotyping. New York: Guilford Press.

Schuller, R. A., Kazoleas, V., \& Kawakami, K. (2009). The impact of prejudice screening procedures on racial bias in the courtroom. Law and Human Behavior, 33(4), 320328. doi:10.1007/s10979-008-9153-9

Skolnick, P., \& Shaw, J. I. (1997). The O.J. Simpson criminal trial verdict: Racism or status shield? Journal of Social Issues, 53(3), 503-516. doi: 10.1111/j.15404560.1997.tb02125.x

Snowball, L., \& Weatherburn, D. (2007). Does racial bias in sentencing contribute to indigenous overrepresentation in prison? Australian and New Zealand Journal of Criminology, 40(3), 272-290. doi:10.1375/acri.40.3.272

Sommers, S. R. (2006). On racial diversity and group decision making: Identifying multiple effects of racial composition on jury deliberations. Journal of Personality and Social Psychology, 90(4), 597-612. doi:10.1037/0022-3514.90.4.597

Sommers, S. R. (2007). Race and the decision making of juries. Legal and Criminological Psychology, 12, 171-187. doi: 10.1348/135532507X89687 
Sommers, S. R., \& Ellsworth, P. C. (2000). Race in the Courtroom: Perceptions of guilt and dispositional attributions. Personality and Social Psychology Bulletin, 26(3), 1367-1379. doi: 10.1177/0146167200263005

Sommers, S. R., \& Ellsworth, P. C. (2001). White juror bias: An investigation of prejudice against Black defendants in the American courtroom. Psychology, Public Policy, and Law, 7(1), 201-229. doi:10.1037//1076-8971.1.1.201

Sommers, S. R., \& Ellsworth, P. C. (2009). "Race salience" in juror decision-making: Misconceptions, clarification, and unanswered questions. Behavioral Sciences \& the Law, 27, 599-609. doi:10.1002/bsl.877.

Sommers, S. R., \& Norton, M. I. (2007). Race-based judgements, race-neutral justifications: Experimental examination of peremptory use and the Batson challenge procedure. Law and Human Behaviour, 31, 261-273. doi:

10.1007/s10979-006-9048-6

Sommers, S. R., Warp, L. S., \& Mahoney, C. C., (2008). Cognitive effects of racial diversity: White individuals' information processing in heterogeneous groups. Journal of Experimental Social Psychology, 44, 1129-1136. doi: 10.1016/j.jesp.2008.01.003

Steblay, N. M., Besirevic, J., Fulero, S. M., \& Lorente, B. (1999). The Effects of pretrial publicity on juror verdicts: A meta-analytic review. Law and Human Behavior, 23(2), 219-235. doi: 10.1023/A:1022325019080

Statistics Canada (2008). Ethnocultural portrait of Canada highlight tables, 2006 Census. Government of Canada. Retrieved from http://www12.statcan.ca/censusrecensement/2006/dp-pd/hlt/97-562/index.cfm?Lang=E 
Stefensmeier, D., Ulmer, J., \& Kramer, J. (1998). The interaction of race, gender, and age in criminal sentencing: The punishment cost of being young and male. Journal of Criminology, 36(4), 763-798. doi:10.1111/j.1745-9125.1998.tb01265.x

Struckman-Johnson, C., Struckman-Johnson, D., \& Miller, M. G. (2008). Effects of Native American race, intoxication and crime severity on judgments of guilt. Journal of Applied Social Psychology, 38(8), 1981-1992. doi:10.1111/j.15591816.2008.00376.x

Sweeney, L. T., \& Haney, C. H. (1992). The influence of race on sentencing: A metaanalytic review of experimental studies. Behavioural Sciences \& the Law, 10(2), 179-195. doi:10.1002/bsl.2370100204

Tabachnick, G. G., \& Fidell, L. S. (2007). Experimental Designs Using ANOVA. Belmont, CA: Duxbury.

Thompson, S., Merrifield, A., \& Chinnery, H. (2011). Are mock jurors influenced by the defendants gender, socioeconomic status and emotional state in forensic medicine? Forensic Medicine, 2(2), 1-21. Retrieved from http://www.webmedcentral.com/article_view/1632

Urban Aboriginal Peoples Study (2010). Urban Aboriginal Peoples Study: Main Report. Toronto: Environics Institute.

U.S. Department of Commerce. (2012). Profile of general population and housing characteristics, 2010 Census. United States Census Bureau. Retrieved from http://factfinder2.census.gov /faces/tableservices/jsf/pages/productview.xhtml?pid=DEC_10_DP_DPDP1 
Vickers, J. (2002). The politics of "race”: Canada, Australia, the United States. Canada: Haymax Inc

Welch, K. (2007). Black criminal stereotypes and racial profiling. The Journal of Contemporary Criminal Justice, 23, 276-288. doi:10.1177/104398620730687

Yassine, A. K., \& Bonta, J. (2009). The offending trajectories of youthful aboriginal offenders. Canadian Journal of Criminology and Criminal Justice, 51(4), 435472. doi: $10.1353 /$ ccj. 0.0070

Zarate, M. A., \& Smith, E. R. (1990). Person categorization and stereotyping. Social Cognition, 8(2), 161-185. doi:10.1521/soco.1990.8.2.161 


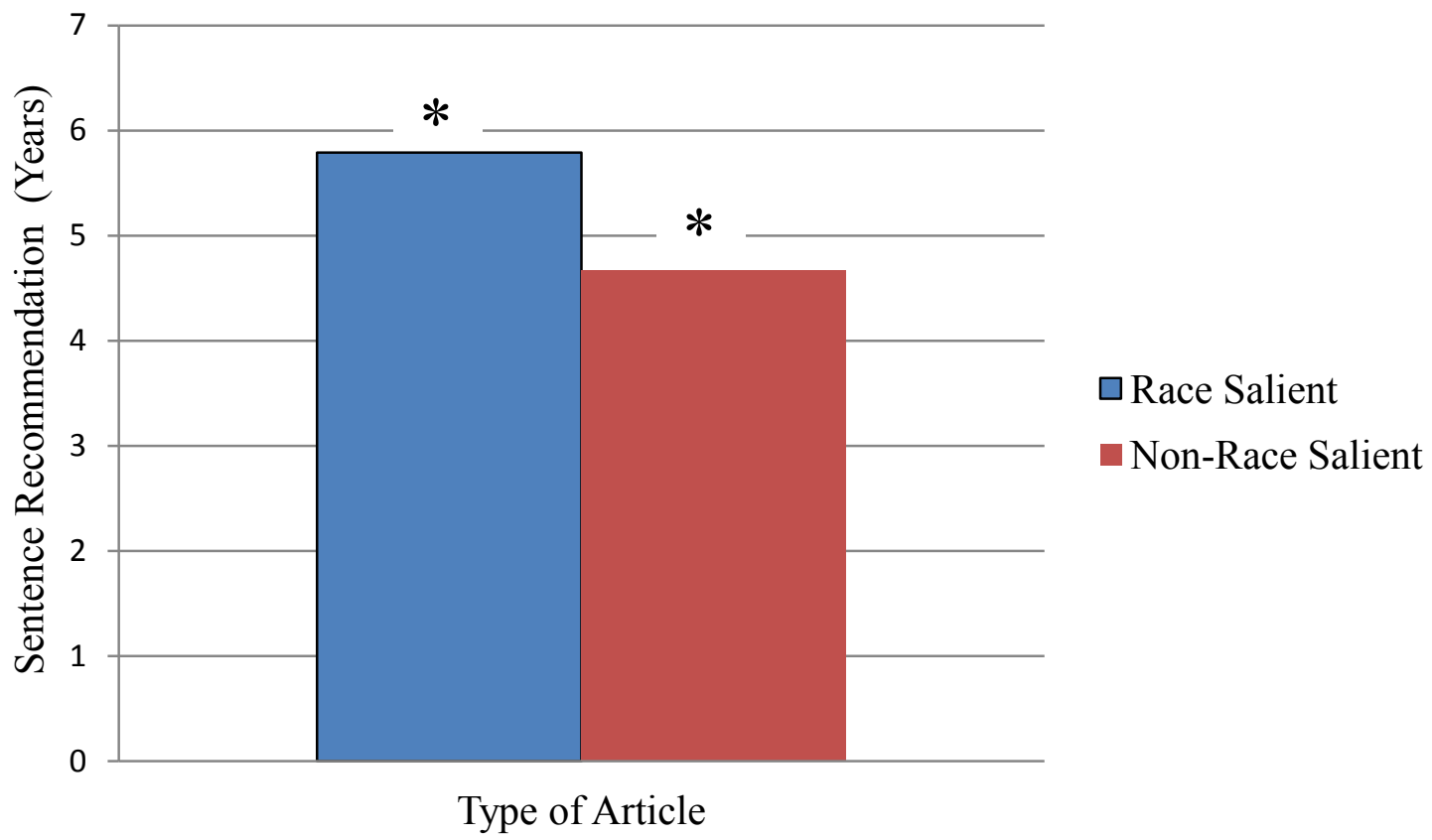

Figure 1. Effect of article type on racialized defendants' sentence recommendation for the DOM charge. Bars marked with an asterisk * are significantly different. 


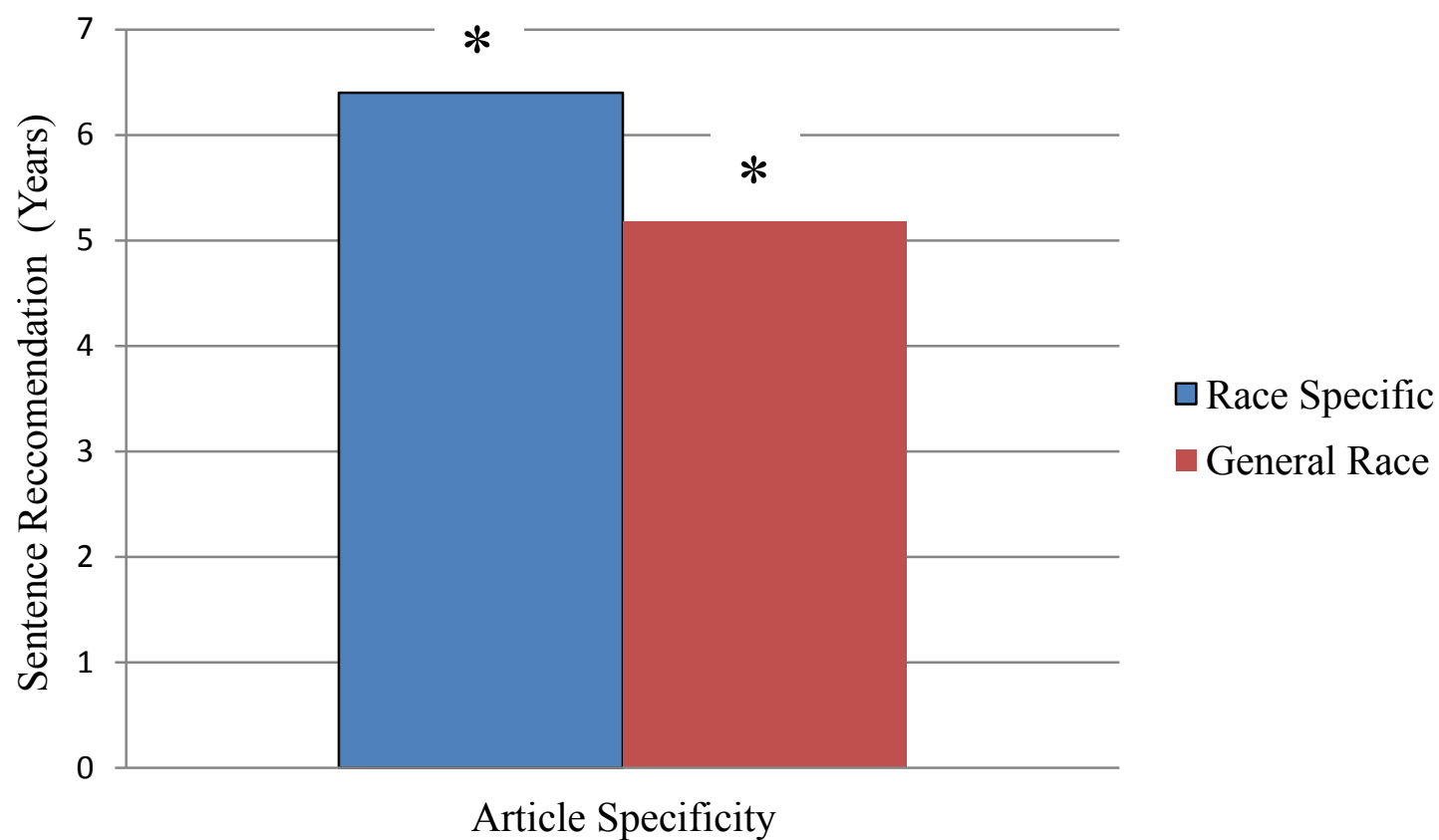

Figure 2. Effect of article specificity on racialized defendants' sentence recommendation for the DOM charge. Bars marked with an asterisk * are significantly different. 


\section{Appendix A \\ News Article - Race Specific (Black or Aboriginal)}

INSTRUCTIONS: We are conducting a pilot study for another experiment involving the readability of online news articles. In order to help with this research, we ask that you briefly review the article below.

\section{Aboriginal/Black Canadians face racism, stereotyping in urban health care centers: Report}

Diana Mehta, The Canadian Press

Published Tuesday, December 11, 2012 6:23AM EST

TORONTO -- A new report suggests Aboriginal/Black Canadians frequently face racism and stereotyping when using health care services in urban centres, a situation which can breed a degree of mistrust deep enough for some to avoid seeking professional help when sick.

The 74-page document, titled "Empathy, dignity, and respect: Creating cultural safety for Aboriginal/Black people in urban health care," was released by the Health Council of Canada on Tuesday.

The independent national agency is now calling for "culturally competent" care and environments in which Aboriginal/Black patients can be treated with understanding and respect.

"When Aboriginal/Black patients present themselves -- whether it's in an emergency room or in any health centre -- they're not necessarily seen for who they are and consequently they're not respected, they're not engaged as fellow human beings and as a result the care they get suffers," John G. Abbott, CEO of the Health Council of Canada told The Canadian Press.

"I think this is one area which has been under reported, understated in the Canadian health care system."

According to the report, while factors like poverty and the impact of colonization are known to have an impact on Aboriginal/ Black health, a "Western approach to health care" often reinforces stereotypes which alienate and intimidate some patients.

As some Aboriginal/Black patients avoid seeking care or drop out of treatment programs, the report says ailments are diagnosed later, when they are harder to treat, and the benefits of preventative care measures, like immunizations and screening tests, may be missed.

"If they're not feeling safe or respected, they're not going to communicate as effectively as they should, and they're not going to follow up on their treatment plan and they're not going to come back," said Abbott. 
The report was based on meetings with health care providers across the country, many of whom were Aboriginal/Black individuals.

In one example shared with researchers, the report said some Aboriginal/Black patients were refused painkillers even when in severe pain because of a belief they were at a higher risk of becoming addicted or were already abusing prescription drugs.

In another, the report said an Aboriginal/Black man who was beaten and bloodied was brought to an emergency room where he was not allowed to lie on a bed. When a doctor asked why, the report said a nurse explained that the man was dirty and would return to the street to engage in the same risky behaviour that had landed him in hospital. In fact, the report said, the patient was employed, owned a home, and had been attacked on his way home from work.

"Part of it is ignorance...some of it racism...part of it is just general stereotyping," said Abbott in detailing the possible reasons for the way many Aboriginal/Black patients say they are treated.

"There is inefficient attention paid to training people on the front lines in particular to really be receptive to a different culture and a different way of life, particularly when they're dealing with healthcare."

The situation is all the more concerning because Aboriginal/Black people often have poorer health and shorter life expectancies than other Canadians, he said.

The report -- which points out that Aboriginal/Black patients often felt most safe when they had some sort of interaction with Aboriginal/Black staff -- suggests having Aboriginal/Black patient navigators and cultural interpreters in place to support patients and healthcare providers, measures which have been a success in some Canadian facilities.

It also suggests an increased emphasis on Aboriginal/Black history and cultural sensitivity during post-secondary and on-the-job training of those in the health sector.

"This is a fairly complicated issue, but there are solutions. But they need to happen at the front line and they need to be supported continuously. It's not so much an issue of money as it is an issue of leadership," Abbott said.

"Many Canadians come up through the mainstream western European model of health care and then when an Aboriginal/Black person comes in ... they're just not exposed to their way of life, their thinking."

The report does point out that cultural competency and cultural safety are becoming a priority for many governments and health care providers, and said many people interviewed while research was being conducted expressed a sense of "hope and anticipation." 
The report will be presented to health officials at provincial and federal levels, and will be shared with health-care providers as well."Individual initiatives are certainly good in themselves but I think each provincial government as well as the federal

government...they really need to put in the policies and programs that make sure this issue is addressed," Abbott said.

"(We must) get to a zero tolerance on this particular aspect of health care." 


\section{Appendix B \\ News Article - General Race}

INSTRUCTIONS: We are conducting a pilot study for another experiment involving the readability of online news articles. In order to help with this research, we ask that you briefly review the article below.

\section{Minority Canadians face racism, stereotyping in urban health care centers: Report}

Diana Mehta, The Canadian Press

Published Tuesday, December 11, 2012 6:23AM EST

TORONTO -- A new report suggests Canada's minorities frequently face racism and stereotyping when using health care services in urban centres, a situation which can breed a degree of mistrust deep enough for some to avoid seeking professional help when sick.

The 74-page document, titled "Empathy, dignity, and respect: Creating cultural safety for minority people in urban health care," was released by the Health Council of Canada on Tuesday.

The independent national agency is now calling for "culturally competent" care and environments in which minority patients can be treated with understanding and respect.

"When minority patients present themselves -- whether it's in an emergency room or in any health centre -- they're not necessarily seen for who they are and consequently they're not respected, they're not engaged as fellow human beings and as a result the care they get suffers," John G. Abbott, CEO of the Health Council of Canada told The Canadian Press.

"I think this is one area which has been under reported, understated in the Canadian health care system."

According to the report, while factors like poverty and the impact of colonization are known to have an impact on minority health, a "Western approach to health care" often reinforces stereotypes which alienate and intimidate some patients.

As some minority patients avoid seeking care or drop out of treatment programs, the report says ailments are diagnosed later, when they are harder to treat, and the benefits of preventative care measures, like immunizations and screening tests, may be missed.

"If they're not feeling safe or respected, they're not going to communicate as effectively as they should, and they're not going to follow up on their treatment plan and they're not going to come back," said Abbott.

The report was based on meetings with health care providers across the country, many of whom were minority individuals. 
In one example shared with researchers, the report said some minority patients were refused painkillers even when in severe pain because of a belief they were at a higher risk of becoming addicted or were already abusing prescription drugs.

In another, the report said a man of minority descent who was beaten and bloodied was brought to an emergency room where he was not allowed to lie on a bed. When a doctor asked why, the report said a nurse explained that the man was dirty and would return to the street to engage in the same risky behaviour that had landed him in hospital. In fact, the report said, the patient was employed, owned a home, and had been attacked on his way home from work.

"Part of it is ignorance...some of it racism...part of it is just general stereotyping," said Abbott in detailing the possible reasons for the way many minority patients say they are treated.

"There is inefficient attention paid to training people on the front lines in particular to really be receptive to a different culture and a different way of life, particularly when they're dealing with healthcare."

The situation is all the more concerning because minority people often have poorer health and shorter life expectancies than other Canadians, he said.

The report -- which points out that minority patients often felt most safe when they had some sort of interaction with minority staff -- suggests having minority patient navigators and cultural interpreters in place to support patients and healthcare providers, measures which have been a success in some Canadian facilities.

It also suggests an increased emphasis on the history of minorities and cultural sensitivity during post-secondary and on-the-job training of those in the health sector.

"This is a fairly complicated issue, but there are solutions. But they need to happen at the front line and they need to be supported continuously. It's not so much an issue of money as it is an issue of leadership," Abbott said.

"Many Canadians come up through the mainstream western European model of health care and then when a minority person comes in ... they're just not exposed to their way of life, their thinking."

The report does point out that cultural competency and cultural safety are becoming a priority for many governments and health care providers, and said many people interviewed while research was being conducted expressed a sense of "hope and anticipation."

The report will be presented to health officials at provincial and federal levels, and will be shared with health-care providers as well. 
"Individual initiatives are certainly good in themselves but I think each provincial government as well as the federal government...they really need to put in the policies and programs that make sure this issue is addressed," Abbott said.

"(We must) get to a zero tolerance on this particular aspect of health care." 


\section{Appendix C \\ News Article - Race Neutral}

INSTRUCTIONS: We are conducting a pilot study for another experiment involving the readability of online news articles. In order to help with this research, we ask that you briefly review the article below.

\section{Health care of top importance to Canadians}

Andrew Vaughan, The Canadian Press

Published Wednesday, July 25, 2012 12:15PM EDT

A new survey says keeping Canada's health care system strong, creating jobs and keeping communities safe are issues of top importance to Canadians. However, that same poll suggests Canadians have little confidence in elected officials' ability to address these issues of concern.

The poll, a joint effort by the Institute for Research on Public Policy and Nanos Research, asked Canadians to rate the importance of a series of policy changes to Canada's future, using a scale of 1 (not at all important) to 10 (very important).

Securing top spot with a score of 9 out of 10 on the importance scale was keeping the country's health care system strong. That was followed by job creation with a rating of 8.7 , and investing in education and ensuring safe communities, which both had a score of 8.4 out of 10 .

"What is interesting is that all of these issues are quite close to the day-to-day lives of Canadians," writes Nik Nanos, president of Nanos Research.

"Can my mother get her hip replaced? Can I keep my job? Will our children have the education they need to prosper? Are we safe in our communities?"

When asked to identify the issue of most importance to them, 24.9 per cent of respondents said health care, followed by 19.7 per cent who said jobs and 9.7 per cent who chose balanced government budgets.

Issues of least importance on the scale included improving the quality of life for Canada's elders and developing Canada's North, both of which received a score of 6.8 out of 10 . Asserting Canada's role in international affairs scored a 7.1.

"Perhaps, in terms of public opinion, being out of sight is also being out of mind," Nanos said of these issues.

While Canadians were clear about the issues of most concern to them, they were also clear in expressing their doubts that elected officials will be able to solve them. 
Of those surveyed, Canadians were twice as likely to say they did not have confidence in governments' ability to solve issues of national concern (18 per cent) than to say they were confident ( 9.4 per cent).

Meanwhile, only 7.1 per cent of Canadians were confident in the ability to find solutions to issues facing their province, compared to 24.3 per cent who were not confident.

Also, when asked if Canada has gotten better or worse at creating solutions to issues of concern, 31.8 per cent of respondents said worse compared to 18.6 per cent who said better.

Nanos writes that issues deemed the most important, such as health care, the aging population and living standards, also received the lowest scores in Canadians' confidence in finding solutions.

When it comes to issues of varying importance, such as natural resources, crime, border protection, trade and international affairs, Canadians were more likely to express confidence in the ability to find solutions.

"One could argue that many of these issues seem to be aligned with the current priorities of the Harper government -- energy and the oilsands, border security, crime and trade," Nanos said.

"This brings into focus the factors that have a major impact on the policy development process. Consider this: If our elected politicians are interested in their own political ends, they will tend to focus on issues that Canadians believe can be solved, while not focusing on issues that Canadians believe are more difficult to solve."

The survey was conducted online between July 5 and July 9. While a total of 2,000 interviews were conducted, the final results included 1,333 individuals. 


\section{Appendix D \\ Article Review}

1. Did the author portray his argument in a clear and concise manner?

_ yes

no

2. Who would this article appeal to?

the general public

healthcare workers

medical students

all of the above

3. What was the authors purpose?

to highlight the importance of healthcare to Canadians

to highlight the need for better training of healthcare staff

I'm not sure

4. Please rate the readability of this article:

$\begin{array}{lllllllll}1 & 2 & 3 & 4 & 5 & 6 & 7 & 8 & 9\end{array}$

Low High 


\section{Appendix E \\ Trial Transcript}

Please read the following carefully

Background Information

Charges: $\quad$ Dangerous Operation of a Motor Vehicle and Impaired Driving Causing Bodily Harm

Defendant: $\quad$ Mark Campbell/Darnell Jackson/ Mahkah Inuk

D.O.B.: October $12^{\text {th }}, 1992$

Arrested: March $16^{\text {th }}, 2012$

(Photograph of the defendant)

Judge: Mark Campbell/Darnell Jackson/ Mahkah Inuk has been charged with sections 249 and 253 of the Canadian Criminal Code; dangerous operation of a motor vehicle causing bodily harm and impaired driving causing bodily harm. Under the law, the Crown has the burden of proving that the defendant is guilty of these charges beyond a reasonable doubt. As jurors, it is your responsibility to decide the facts, to listen to all evidence, and to apply the law that I will give you at the end of the trial. The case will commence with the Crown and the Defence giving opening statements. Each party will then present and question witnesses as well as law enforcement personnel who will be subsequently cross-examined. Following the testimonies you will be asked to make a decision as to whether the defendant is guilty or not guilty.

Crown Opening Statement: The Crown will prove that Mark Campbell/Darnell Jackson/Mahkah Inuk drove in a reckless and impaired manner that resulted in the broken wrist of Renee Pangborn. On the day of March 15, $2012 \mathrm{Mr}$.

Campbell/Jackson/Inuk was running errands with his girlfriend, Renee Pangborn. While driving along the 401, Mr. Campbell's/Jackson's/Inuk's pickup veered to the left, crossed the lanes of traffic, and collided head-on with a large tree. The crown will prove that Mr. Campbell's/Jackson's/Inuk's reckless behaviour was careless and remorseless. We will provide a witness that saw Mark Campbell/Darnell Jackson/Mahkah Inuk driving under the influence, and show that he was in possession of "dust off", a compressed air product that acted as the basis for the crime. As a consequence of his actions, it is your duty as representatives of the community to seek justice by finding $\mathrm{Mr}$. Campbell/Jackson/Inuk guilty of dangerous operation of a motor vehicle causing bodily harm and impaired driving causing bodily harm.

Defence's Opening Statement: The Crown is going to tell you a wonderful tale during this trial. They are going to try to piece together some loose bits of evidence, fill in the gaps with a couple of coincidences, and try to glue it all together with some pretty slippery arguments to convince you that my client is a criminal. The problem with the Crown's story is that my client is not the villain in this tale. The Defence will show that the pieces of evidence don't fit together, that the gaps are too big to be filled with mere 
coincidences and that the Crown's speculative arguments cannot hold it all

together. Mark Campbell/Darnell Jackson/Mahkah Inuk is an innocent man, and you, the jury, will be the real villains if you send this innocent man to jail.

\section{The Crown calls their first witness, Jennifer Switzer to take the stand.}

Crown: Please state your full name for the court, and your affiliation with this case.

Switzer: My full name is Jennifer Ann Switzer, and I was a witness to the accident.

Crown: What did you see on March $15^{\text {th }}$ ?

Switzer: I saw the vehicle in front of us driving recklessly. It was swerving from one side of the lane to the other.

Crown: Did the driver seem intoxicated?

Switzer: I wasn't sure if the driver was intoxicated, or just nodding off. The vehicle seemed to be driving normal one minute and erratically the next.

Crown: Did you report the suspicious behaviour?

Switzer: I did. I called 911.

Crown: Then what happened?

Switzer: As I was describing the vehicle to the 911 operator, the truck veered sharply into the left lane of traffic, before hitting a tree. I yelled to the operator that there was a horrible accident and that ambulances were needed immediately.

Crown: How long was it before the ambulance arrived?

Switzer: Couldn't have been more than 5 minutes, everything seemed to happen so fast.

The Crown calls their second witness, Officer Bill Norman to take the stand.

Crown: Did you receive a call of a reckless driver on March 15th?

Officer Norman: Yes, a report came in that a there had been a collision in the left lane of the 401 just west of Mississauga.

Crown: What did you see when you arrived at the scene?

Officer Norman: On scene, a black Ford pickup and a large tree were fused together. The vehicle had substantial damages. There were also two sets of paramedics present.

One set was treating a/an White/Black/Aboriginal-Canadian male who was on a stretcher. I was informed that this was Mark Campbell/Darnell Jackson/Mahkah Inuk, the defendant. The other set was working on getting a female out of the vehicle, who was Mark Campbell/Darnell Jackson/Mahkah Inuk's girlfriend, Renee Pangborn.

Crown: Were there any indications as to the cause of the incident?

Officer Norman: Yes. It appeared as though the Ford pickup was driving west in the right hand lane, when the driver lost control, veering into oncoming traffic. 
Crown: How did you continue your investigation?

Officer Norman: While paramedics were tending to Mr. Campbell/Jackson/Inuk, I interviewed Renee Pangborn.

Crown: Proceed.

Officer Norman: She indicated that she didn't know how the wreck occurred. She was looking at something in her lap, she said, and the next thing she knew, the car had crashed into a tree. She explained that Mr. Campbell/Jackson/Inuk had been complaining of a headache. When I questioned whether this was normal for the defendant, she hesitated. Her story seemed odd to me. I mentioned that the paramedics said that Mr. Campbell/Jackson/Inuk's eyes were dilated. I then informed Ms. Pangborn that we would be gathering a urine and blood sample from Mr. Campbell/ Jackson/Inuk and that she was compelled by law to disclose any relevant information. It was at this time that Ms. Pangborn disclosed that Mr. Campbell/Jackson/Inuk frequently huffed "dust off", a compressed air product that affects muscle control. This information was consistent with the empty "dust off" cans found amidst the debris of the accident and wedged between the driver's seat. We believe this to be the cause of Mr. Campbell/Jackson/Inuk's reckless behaviour. He was later arrested in hospital for dangerous operation of a motor vehicle causing bodily harm and impaired driving causing bodily harm.

The Defence cross-examines the witness:

Defence: Officer Norman, did you interview my client at the time of the event in question?

Officer Norman: No, I did not. Mr. Campbell/Jackson/Inuk was being transported to the nearest hospital. The only words we exchanged were in regards to the urine/blood samples that are standard collection in all crashes of this magnitude.

Defence: And did Mr. Campbell/Jackson/Inuk appear to be under the influence? Officer Norman: Well, he was definitely exhibiting some unusual signs. He was stuttering and his eyes were dilated.

Defence: And did Mr. Campbell/Jackson/Inuk oppose the collection of the samples? Officer Norman: No he did not. We were able to collect the samples and bring them to a toxicology specialist.

Defence: Mr. Campbell/Jackson/Inuk had a few cans of compressed air in his pickup. Sounds like this is something you would find in any construction worker's truck. Officer Norman: Well, the substance in question is consistent with Ms. Pangborn's statement, Mr. Campbell/Jackson/Inuk's behaviour, and was within Mr. Campbell/Jackson/Inuk's reach at the time of the incident.

Defence: I see. Now let's review your theory - you believe that Mr.

Campbell/Jackson/Inuk inhaled the "dust off" before getting in his vehicle to run errands, causing him to lose control of his vehicle. 
Officer Norman: Yes, I am convinced this is what happened.

Defence: And you do you have any witnesses who saw Mr. Campbell/Jackson/Inuk consume the "dust off"?

Officer Norman: No. But I have a witness that can attest to Mr.

Campbell/Jackson/Inuk's state at the time of the offence.

Defence: So your theory is just a theory.

The Crown calls their third witness, Renee Pangborn and she takes the stand.

Crown: Ms. Pangborn, it is my understanding that you are the defendant's girlfriend, is this correct?

Pangborn: No, we aren't together anymore.

Crown: Did the breakup result from the events that unfolded on March $15^{\text {th }}$ ?

Pangborn: I guess you could say that.

Crown: Could you please elaborate further Ms. Pangborn?

Pangborn: There's not much to say. Mark/Darnell/Mahkah and I were struggling to make ends meet. We both picked up a few extra shifts a week to help with the bills. Things got pretty stressful around the house. The stress only intensified Mark/Darnell/Mahkah's chronic headaches. He was always moody and nothing I did was right. This was my breaking point, everything became too much.

Crown: Did Mr. Campbell/Jackson/Inuk ever seek medical treatment to help relieve the pain?

Pangborn: Mark/Darnell/Mahkah would never be caught dead in a doctor's office. He had his own way of dealing with things.

Crown: Are you referring to the "dust off" Officer Norman alluded to earlier?

Pangborn: Yes. Mark/Darnell/Mahkah always said that huffing the "dust off" did more for him than any doctor ever could. He was a frequent user, sometimes going through 20 or more cans a week.

Crown: And is it your understanding that Mr. Campbell/Jackson/Inuk's consumption of the "dust off" was the cause of his erratic driving?

Pangborn: I know it was! Every time he does it he gets all drowsy. Sometimes he can't even walk. It's like the chemicals melt his muscles, he becomes limp.

Crown: And Ms. Pangborn, how has this accident impacted you? 
Pangborn: During the accident my arm was crushed by the door, resulting in a broken wrist. Since I work as a receptionist and my job involves a lot of typing, I was off work for a month. I had to move back in with my mother because I couldn't afford rent.

Crown: Thank you Ms. Pangborn.

The Defence cross-examines the witness:

Defence: Ms. Pangborn, you claim that you've seen the defendant huff "dust off" before? Pangborn: Yes, all the time.

Defence: And did you see Mr. Campbell/Jackson/Inuk consume "dust off" on the day of the offence?

Pangborn: No, Mark/Darnell/Mahkah had just gotten off of work. He picked me up about 5 minutes prior to the accident. We were on our way to pick up some groceries.

Defence: So you have no actual proof that Mr. Campbell/Jackson/Inuk huffed "dust off' on the day of the accident.

Pangborn: Well I mean I didn't see him consume it, but I know he did. He was complaining of a headache before he left for work that morning. In our house, that can only mean one thing. Not to mention he was acting strange, almost delirious.

Defence: Having a headache is a pretty common occurrence; many people complain about headaches daily. On top of that there is no one who saw Mr. Campbell/Jackson/ Inuk ingest anything. Isn't it possible Ms. Pangborn that Mr. Campbell/Jackson/Inuk was just tired and nodded off at the wheel?

Pangborn: That may be what he wants you to think, but it's not the truth!

Defence: But did you not say that Mr. Campbell/Jackson/Inuk had taken on extra shifts to help with the bills?

Pangborn: Yes he did. He works about 50 hrs a week. But I mean, so do I.

Defence: So essentially Mr. Campbell/Jackson/Inuk's behaviour reminded you of someone who had consumed "dust off," so you assumed that was the reason for Mr. Campbell/Jackson/Inuk's actions.

The Defence calls their first witness, Dr. Brian Scherania, and he takes the stand.

Defence: Can you please state your name and occupation for the court?

Dr. Scherania: Yes. My name is Dr. Brian Scherania, I am a toxicologist working at the Health Science Center. 
Defence: And what are your credentials?

Dr. Scherania: I have a medical degree and have been practicing toxicology for 20 years now.

Defence: What were the samples you received from Mr. Campbell/Jackson/Inuk? Dr. Scherania: I received a urine and blood sample from Mr. Campbell/ Jackson/ Inuk. Standard procedure is to perform a 10-panel urine/blood screen. These tests are checking for substances including but not limited to: amphetamines, barbiturates, benzodiazepines, cannabinoids, cocaine, methadone, methaqualone, opiates, phencyclidine and propoxyphene.

Defence: Could you describe to the court what you learned from the testing?

Dr. Scherania: Certainly. We did not find any traces of these controlled substances.

Defence: And what about any traces of compressed air?

Dr. Scherania: The tests did not reveal any traces of difluoroethane, the active ingredient in "dust off."

Defence: Interesting. Might it be fair to say that Mr. Campbell/Jackson/Inuk's state could have been the result of simple exhaustion?

Dr. Scherania: I suppose that is a possibility.

Crown: So to your knowledge, there is no sign that Mr. Campbell/ Jackson/ Inuk's symptoms were a direct result of the drug?

Dr. Scherania: No, not to my knowledge.

The Crown cross-examines the witness:

Crown: Dr. Scherania, could you please elaborate on your credentials?

Dr. Schrania: Yes. I graduated from the Pharmacology and Toxicology program at Queen's University in 1992. From there I worked in environmental toxicology for 5 years. I then changed my focus to concerns of human toxicity in 1997. As it stands, I have been working as a lab technician at the Health Science Center for the past 15 years.

Crown: So to clarify, you are not an expert on sleeping patterns.

Dr. Scherania. Correct.

Crown: And Dr. Scherania, could you please describe the effects difluoroethane has on the body when consumed.

Dr. Scherania: The active ingredient in compressed air, when inhaled, causes a very rapid intoxication phase, a euphoric phase and a very fast high. This can at times result in loss of consciousness and loss of muscle control. Basically, the inhalants produce an effect similar to alcohol intoxication.

Crown: I see. So could Mr. Campbell/ Jackson/Inuk's reckless behaviour have resulted from "dust off" inhalation? 
Dr. Scherania: It is possible. But there were no traces of difluoroethane in the battery of tests ran.

Crown: But isn't it true Dr. Scherania that many substances have a strict detection period after which a substance can return negative results?

Dr. Scherania: Yes, this is true.

Crown: And what is the amount of time before difluoroethane is untraceable in an individual's urine/blood stream?

Dr. Scherania: Approximately an hour.

Crown: So Dr. Scherania, how can you be sure that the toxicology report was administered within the hour of Mr. Campbell/Jackson/Inuk's consumption?

Dr. Scherania: There is no scientific way of knowing. I can only report the toxicology results, which suggest that Mr. Campbell/Jackson/Inuk did not appear to have any toxins in his system at the time the test was administered.

Crown: So these tests cannot conclusively say that Mr. Campbell/Jackson/Inuk didn't consume the drug on the day in question.

Dr. Scherania: No, they cannot.

The Defence calls their second witness, Mark Campbell/Darnell Jackson/Mahkah Inuk, and he takes the stand.

Defence: What did you do on the day of March 15, 2012?

Campbell/Jackson/Inuk: I woke up, ate breakfast, worked a 12 hour day, and had just picked Renee up to get some groceries.

Defence: And Mr. Campbell/Jackson/Inuk, can you please disclose to the court what it is you do for a living?

Campbell/Jackson/Inuk: I work as a construction worker.

Defence: Do you work extended shifts often?

Campbell/Jackson/Inuk: I probably work about 3 extended shifts per week.

Defence: And when you work these shifts, you must get pretty tired?

Campbell/Jackson/Inuk: You have no idea. By the time I get home I'm exhausted. My body hurts, and all I want to do is sleep.

Defence: Sleeping must be awfully difficult with the constant headaches you experience. Campbell/Jackson/Inuk: It is. It's a constant struggle.

Defence: Now were the tools and cans of "dust off" found at the scene of the accident yours?

Campbell/Jackson/Inuk: Yes. I usually leave everything I have in my truck. 
Defence: So my client is a hardworking man that also happened to have the substance in question in his truck. This hardly seems like enough evidence to brand him a criminal.

The Crown cross-examines the witness.

Crown: Mr. Campbell/ Jackson/ Inuk how can you account for your reckless driving on March 15th?

Campbell/Jackson/Inuk: I was tired. Construction is hard work.

Crown: And can you please describe a typical day at work.

Campbell/Jackson/Inuk: We usually start pretty early. We all meet up at the site and it's my responsibility to pick up the materials for the day's work.

Crown: Therefore, the "dust off" is not required for the tasks you perform, correct? Campbell/Jackson/Inuk: I guess not

Crown: So Mr. Campbell/Jackson/Inuk how does "dust off” work into this routine, what exactly do you use it for at work?

Campbell/Jackson/Inuk: I keep it on hand in case anyone needs it.

Crown: And what are they using it for?

Campbell/Jackson/Inuk: Clean up once everything is said and done.

Crown: Then tell me, why do you need so many, and do they not have some of their own.

Campbell/Jackson/Inuk: We go to several different sites a day. I don't know why they don't bring their own.

Crown: And Mr. Campbell/Jackson/Inuk have you ever thought of seeking medical treatment for your condition?

Campbell/Jackson/Inuk: You go to the doctor if you're dying, not for a headache.

Crown: Let me ask you point blank, Mr. Campbell/Jackson/Inuk, did you huff "dust off' before picking up Ms. Pangborn, to relieve your headache?

Campbell/Jackson/Inuk: No way.

Crown: So you say Mr. Campbell/Jackson/Inuk. The evidence says something different.

The Defence Re-directs the cross-examination:

Defence: Mr. Campbell/Jackson/Inuk, when Officer Norman approached you for medical samples while you were in a vulnerable state, you gave them willingly. Why did you do that?

Campbell/Jackson/Inuk: I don't remember being asked for the samples. I guess I was just trying to help out. 
Crown Closing Statement: The defendant, Mr. Campbell/Jackson/Inuk, was experiencing constant headaches. He needed some way to relieve the pain. But there was one way, wasn't there? He inhaled the "dust off" he kept with him in the back of his truck. When Mr. Campbell/Jackson/Inuk was driving for groceries the active ingredient started to take effect. It was at this time that Mr. Campbell/Jackson/Inuk was seen swerving across lanes of traffic before eventually crashing into a tree. How do we know this? First, the defendant experiences constant headaches for which he has never sought medical treatment. Second, Mr. Campbell/Jackson/Inuk was seen exhibiting signs of drowsiness and a lack of muscle control before the incident. Symptoms consistent with inhalants such as dust off. Third, a can of the inhalant was found at the scene of the crime and the only reason he agreed to the samples was because he knew they would be tested after the detection period. There is no doubt that his substance belonged to $\mathrm{Mr}$.

Campbell/Jackson/Inuk. Can all these be mere coincidences, as the defence would have you believe? No, you and I both know that this goes beyond a series of coincidences, beyond any reasonable doubt -- the defendant, ark Campbell/Darnell Jackson/Mahkah Inuk, did commit the crime for which he stands accused. He chose to drive while high on "dust off", and his actions resulted in the bodily harm of his own girlfriend, Renee Pangborn. You can restore justice by finding him guilty of these charges.

\section{Defence's Closing Statement: Mark Campbell/Darnell Jackson/Mahkah Inuk} thought it was just another day. He woke up at his normal time, went off to work, and was going to run some errands. Before he knew it, the cops were asking him for samples to test their suspicion for a crime he did not commit. When the police asked for the samples Mr. Campbell/Jackson/Inuk, gave them willingly. The only evidence that links my client to this offence is the can of 'dust off'. But, ladies and gentlemen, does that mean he committed the crime, or that he is one of many construction workers who carries "dust off" with them to sites. I have to ask myself, if he inhaled the "dust off", why didn't the toxicologist find any traces of it? There simply is no credible evidence to demonstrate that my client committed this crime. If my client really had been guilty, would he have let the police take the samples willingly? Come on, folks, the Crown is trying to piece together a puzzle, and they don't have enough pieces. Without all those pieces, you must find there's plenty of room for doubt and return a verdict of not guilty.

Crown Rebuttal: Criminals sometimes think they are smarter than the rest of us. But if that was true, they would not commit the crime in the first place. So just because a defendant let the police take samples doesn't mean that he didn't commit the crime. Maybe he knew that the substance would be untraceable by the time the samples would be tested. He thought the drive would go smoothly, showing a complete disregard for the safety of others. We have demonstrated that the defendant had a reason and opportunity to commit the crime. The Defence never challenged that. We found a 
witness who saw the defendant driving recklessly, and all the Defence could do is try to make you doubt what the witness saw. We then offered physical evidence by way of a can of 'dust off' matching the police statement and the one found at the scene. The Defence spins some fantasy about how this could have happened, but offers no evidence for their story. The Defence would like you to believe that anything short of a videotape of the defendant inhaling the substance is insufficient evidence. Well, folks, that is not true. You can send that message to the defence by finding the defendant, Mark Campbell/ Darnell Jackson/Mahkah Inuk, guilty. 


\section{Appendix F \\ Jury Instructions}

Judge: Members of the jury, you have heard the testimony from a number of witnesses. It is now my responsibility to provide you with the law.

\section{Presumption of Innocence}

[1] Every person charged with an offence is presumed to be innocent, unless and until the Crown has proved his/her guilt beyond a reasonable doubt.

[2] The indictment tells you and Mark Campbell/Darnell Jackson/Mahkah Inuk what offence the Crown alleges against Mark Campbell/Darnell Jackson/Mahkah Inuk. The charge is not evidence. It is not proof of guilt.

[3] The presumption of innocence lasts throughout the trial. This presumption only ceases to apply if, at the end of the case and on the whole of the evidence, the Crown has proved beyond a reasonable doubt that Mark Campbell/Darnell Jackson/Mahkah Inuk is guilty of the crime charged.

\section{Burden of Proof}

[1] The person charged does not have to present evidence or prove anything in this case, in particular, that he/she is innocent of the offence charged.

[2] From start to finish, it is the Crown who must prove the guilt of Mark

Campbell/Darnell Jackson/Mahkah Inuk beyond a reasonable doubt. You must find Mark Campbell/Darnell Jackson/Mahkah Inuk not guilty of the offence unless the Crown proves beyond a reasonable doubt that he is guilty of it.

Finally, I will remind you that Mr. Campbell/Jackson/Inuk is charged with dangerous operation of a motor vehicle and impaired driving causing bodily harm:

Section 249 of the Criminal Code states every one commits offence who operated

(a) a motor vehicle in a manner that is dangerous to the public, having regard to all the circumstances, including the nature, condition and use of the place at which the motor vehicle is being operated and the amount of traffic that at the time is or might reasonably be expected to be at that place.

Section 253 of the Criminal Code states that every one commits an offence who operates a motor vehicle or vessel or operates or assists in the operation of an aircraft or of railway equipment or has the care or control of a motor vehicle, vessel, aircraft or railway equipment, whether it is in motion or not,

(a) While the person's ability to operate the vehicle, vessel, aircraft or railway equipment is impaired by alcohol or a drug 
Punishment

249 DANGEROUS OPERATION OF A MOTOR VEHICLE - Everyone who commits a dangerous operation of a motor vehicle is guilty of an indictable offence and is liable to imprisonment for a term not exceeding five years.

255. (2) IMPAIRED DRIVING CAUSING BODILY HARM - Everyone who commits an offence under section 253 is guilty of an indictable offence and liable to imprisonment for life.

Please take into consideration all the information you have heard today, and do not let any biases you have come into your decision making process. 


\section{Appendix G \\ Juror Questionnaire}

INSTRUCTIONS: Please respond to the following items with regards to the dangerous operation of a motor vehicle charge against the defendant.

1. How do you find the defendant, Mark Campbell/Darnell Jackson/Mahkah Inuk?

GUILTY

NOT GUILTY

2. How confident do you feel in your verdict?

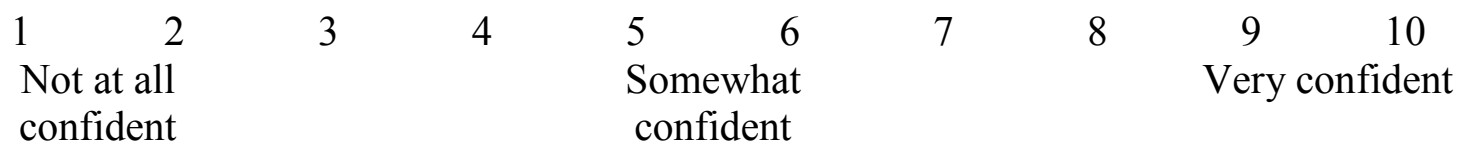

3. Please answer if you voted GUILTY above. What (if any) punishment do you believe the defendant deserves?

$\begin{array}{ccccccccc}1 & 2 & 3 & 4 & 5 & 6 & 7 & 8 & \begin{array}{c}10 \\ \text { The maximum } \\ \text { No punishment } \\ \text { allowed by law }\end{array}\end{array}$

INSTRUCTIONS: Please respond to the following items with regards to the impaired driving causing bodily harm charge against the defendant.

1. How do you find the defendant, Mark Campbell/Darnell Jackson/Mahkah Inuk?

GUILTY

NOT GUILTY

2. How confident do you feel in your verdict?

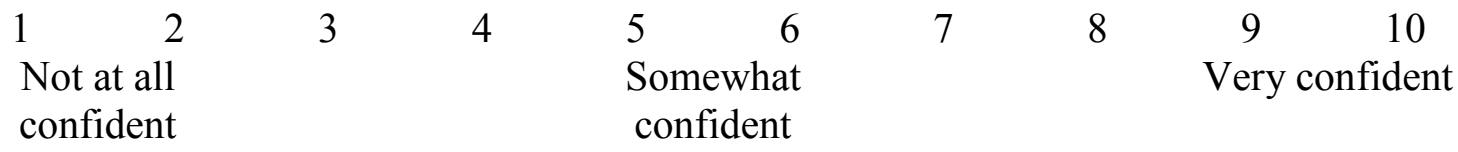

3. Please answer if you voted GUILTY above. What (if any) punishment do you believe the defendant deserves?

$\begin{array}{ccccccccc}1 & 2 & 3 & 4 & 5 & 6 & 7 & 8 & 9 \\ \text { No punishment } & & & & & & & \begin{array}{c}\text { The maximum } \\ \text { punishment }\end{array}\end{array}$


allowed by law

4. How strong was the evidence presented by the Crown?
12
3
4
5
6
7
8
9

Very weak

Very strong

5. How strong was the evidence presented by the Defence?
12
3
4
5
6
7
8
9

Very weak

Very strong

6. How clear were the jury instructions in helping you to determine whether the defendant was guilty?
12
3
4
5
6
7
89

Not clear at all

Very clear

7. How well do you feel you understood the jury instructions provided in this case?
12
3
4
5
6
$\begin{array}{ll}7 & 8\end{array}$
9

Not at all

Completely

8. To what extent did you rely on the jury instructions when making your verdict decision in this case?
12
3
4
5
6
7
8
9

Not at all - I

relied completely

on other factors

Completely - I used only the instructions to reach my decision

The next set of questions will involve your perceptions of the defendant, Mark

\section{Campbell/Darnell Jackson/Mahkah Inuk:}

1. To what extent is the crime due to his personality/character or to the environment/situation?

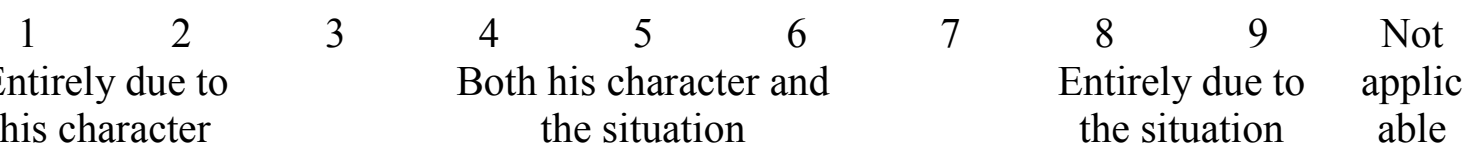

2. To what extent does the crime reflect him or society? 


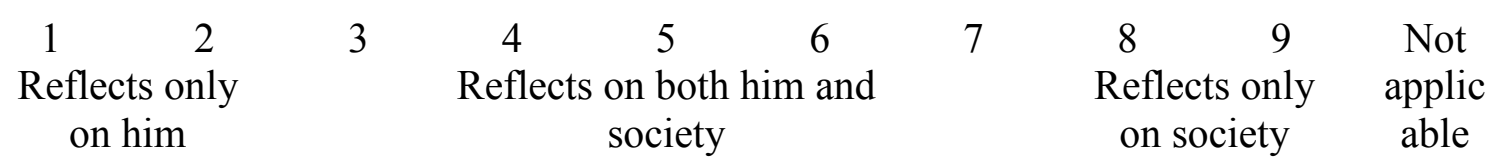

3. To what extent is the crime due to personal or societal reasons?

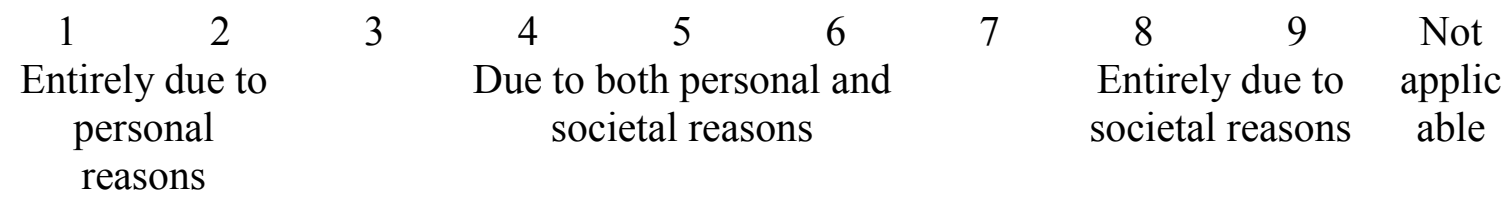

4. What is the likelihood that this defendant would commit the same crime again in the future?

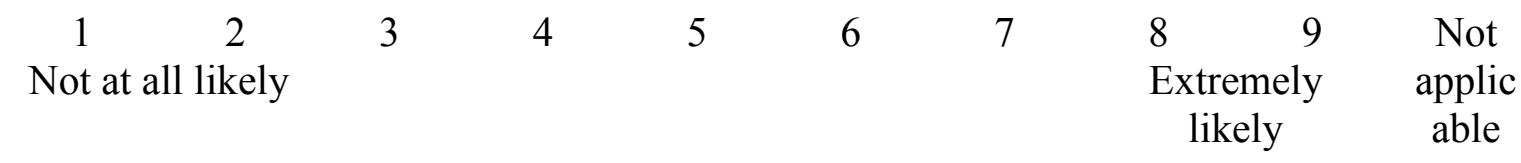

5. What is the likelihood that this defendant would commit any crime in the future?

$\begin{array}{cccccccccc}1 & 2 & 3 & 4 & 5 & 6 & 7 & 8 & 9 & \begin{array}{c}\text { Not } \\ \text { applic } \\ \text { Not at all likely }\end{array} \\ & & & & & & \text { likely } & \text { able }\end{array}$

6. What is the likelihood that this defendant will reform and not commit any crimes in the future?

$\begin{array}{cccccccccc}1 & 2 & 3 & 4 & 5 & 6 & 7 & 8 & 9 & \begin{array}{c}\text { Not } \\ \text { applic } \\ \text { Not at all likely }\end{array} \\ & & & & & & \text { likely } & \text { able }\end{array}$

7. Did the defendant intend to commit the crime?

$\begin{array}{cccccccccc}1 & 2 & 3 & 4 & 5 & 6 & 7 & 8 & 9 & \begin{array}{c}\text { Not } \\ \text { applic } \\ \text { Not at all likely }\end{array} \\ & & & & & & \text { Extremely } \\ \text { likely } & \end{array}$

8. Was the defendant able to foresee the outcome of his behaviour?

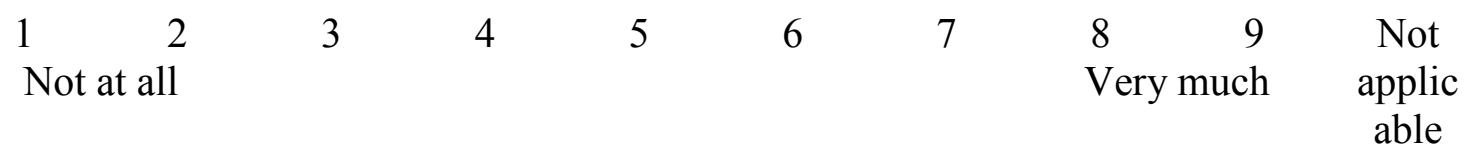

9. How responsible is the defendant for his behaviour?

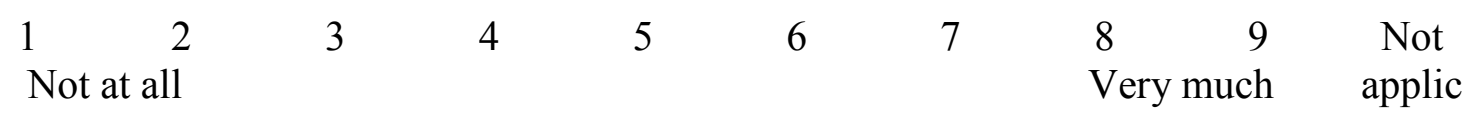


able

10. What was the race of the defendant, Mark Campbell/Darnell Jackson/ Mahkah Inuk?

Asian

Black/African-Canadian

East Indian

Hispanic/Latino

White/Caucasian/Anglo

Aboriginal Canadian/Native Canadian/First Nations

I do not know

11. What was the defendant's occupation?

He was a truck driver

He was a construction worker

He was between jobs

12. Do you feel that race and racial issues featured prominently in this trial? Yes No 


\section{Adjective Checklist - Cultural Stereotype}

Below is a list of adjectives. We would like you to indicate the degree to which the words below represent part of the cultural stereotype of Whites/Blacks/Aboriginal-

Canadians. (what is the culturally-held stereotype about this group, NOT your personal beliefs).

\begin{tabular}{|c|c|c|c|c|c|c|}
\hline Honest & 1 & 2 & 3 & 4 & 5 & 6 \\
\hline Deceitful & 1 & 2 & 3 & 4 & 5 & 6 \\
\hline Radical & 1 & 2 & 3 & 4 & 5 & 6 \\
\hline Faithful & 1 & 2 & 3 & 4 & 5 & 6 \\
\hline Suspicious & 1 & 2 & 3 & 4 & 5 & 6 \\
\hline Uneducated & 1 & 2 & 3 & 4 & 5 & 6 \\
\hline Courteous & 1 & 2 & 3 & 4 & 5 & 6 \\
\hline Impulsive & 1 & 2 & 3 & 4 & 5 & 6 \\
\hline Hostile & 1 & 2 & 3 & 4 & 5 & 6 \\
\hline Ambitious & 1 & 2 & 3 & 4 & 5 & 6 \\
\hline Friendly & 1 & 2 & 3 & 4 & 5 & 6 \\
\hline Cruel & 1 & 2 & 3 & 4 & 5 & 6 \\
\hline Dangerous & 1 & 2 & 3 & 4 & 5 & 6 \\
\hline Addict & 1 & 2 & 3 & 4 & 5 & 6 \\
\hline Kind & 1 & 2 & 3 & 4 & 5 & 6 \\
\hline Violent & 1 & 2 & 3 & 4 & 5 & 6 \\
\hline Quick-tempered & 1 & 2 & 3 & 4 & 5 & 6 \\
\hline Aggressive & 1 & 2 & 3 & 4 & 5 & 6 \\
\hline Criminal & 1 & 2 & 3 & 4 & 5 & 6 \\
\hline Phony & 1 & 2 & 3 & 4 & 5 & 6 \\
\hline
\end{tabular}




\section{Adjective Checklist - Personal Beliefs}

Now we would like you to indicate the degree to which the words below represent part of your personal beliefs about Whites/Blacks/Aboriginal-Canadians.

Not at all

Very Much

\begin{tabular}{|c|c|c|c|c|c|c|}
\hline Honest & 1 & 2 & 3 & 4 & 5 & 6 \\
\hline Deceitful & 1 & 2 & 3 & 4 & 5 & 6 \\
\hline Radical & 1 & 2 & 3 & 4 & 5 & 6 \\
\hline Faithful & 1 & 2 & 3 & 4 & 5 & 6 \\
\hline Suspicious & 1 & 2 & 3 & 4 & 5 & 6 \\
\hline Uneducated & 1 & 2 & 3 & 4 & 5 & 6 \\
\hline Courteous & 1 & 2 & 3 & 4 & 5 & 6 \\
\hline Impulsive & 1 & 2 & 3 & 4 & 5 & 6 \\
\hline Hostile & 1 & 2 & 3 & 4 & 5 & 6 \\
\hline Ambitious & 1 & 2 & 3 & 4 & 5 & 6 \\
\hline Friendly & 1 & 2 & 3 & 4 & 5 & 6 \\
\hline Cruel & 1 & 2 & 3 & 4 & 5 & 6 \\
\hline Dangerous & 1 & 2 & 3 & 4 & 5 & 6 \\
\hline Addict & 1 & 2 & 3 & 4 & 5 & 6 \\
\hline Kind & 1 & 2 & 3 & 4 & 5 & 6 \\
\hline Violent & 1 & 2 & 3 & 4 & 5 & 6 \\
\hline Quick-tempered & 1 & 2 & 3 & 4 & 5 & 6 \\
\hline Aggressive & 1 & 2 & 3 & 4 & 5 & 6 \\
\hline Criminal & 1 & 2 & 3 & 4 & 5 & 6 \\
\hline Phony & 1 & 2 & 3 & 4 & 5 & 6 \\
\hline
\end{tabular}


Finally, we would like you to indicate the degree to which you agree with the statements listed below.

Strongly Disagree

Agree
Disagree Somewhat

2
Agree Somewhat

3
Strongly

4

1. It is really a matter of some people not trying hard enough: If Blacks/Aboriginal-Canadians would only try harder they could be just as well off as everyone else.
1
2
3
4

2. There are times when a trial judge should take an offender's Black/Aboriginal-Canadian status into account when making sentencing decisions. 1
2
3
4

3. Many other minorities overcame prejudice and worked their way up; Blacks/AboriginalCanadians should do the same. 1 2 3

4

4. Black/Aboriginal-Canadian leaders have been trying to push too fast in terms of their progress. $1 \quad 2 \quad 3 \quad 34$

5. Discrimination against Blacks/Aboriginal-Canadians is no longer a problem in Canada. $1 \quad 2 \quad 3 \quad 4$

6. Over the past few years, Blacks/Aboriginal-Canadians have gotten more than they deserve. 1 2 3 4

7. The over-representation of Blacks/Aboriginal-Canadians in prisons is a major social problem in Canada today.

1

3

4

8. The little discrimination against Blacks/Aboriginal-Canadians in Canada today does not limit their chances to get ahead.
1
2
3
4

9. Over the past few years, Blacks/Aboriginal-Canadians have gotten more economically then they deserve.

1

2

3

4

10. Generations of discrimination have created conditions that make it difficult for Blacks/AboriginalCanadians to work their way out of the lower socioeconomic group.

1

2

3 


\section{Demographics}

31. What is your gender?

Man

Woman

Trans

Other (please

specify):

32. What is your racial/ethnic background?

Asian

Black/African-Canadian

Middle Eastern

East Indian

Hispanic/Latino

White/Caucasian

Aboriginal Canadian/Native Canadian/First Nations

Other (please specify)

33. What is your political affiliation?

Conservative Party

Liberal Party

New Democratic Party

Green Party

Le Bloc Quebecois

I have no political affiliations

34. What is the highest level of education that you have obtained?

Doctoral or professional degree

Master's degree

Bachelor's degree

Associate's degree

Postsecondary non-degree award

Some college, no degree

High school diploma or equivalent

Less than high school 


\section{Appendix $\mathbf{H}$ \\ Informed Consent}

The purpose of an informed consent is to make sure that you understand the purpose of the study and your involvement as a participant. The informed consent must include enough information regarding the study for you to be able to make a well-informed decision regarding whether or not you would like to partake in the study.

Present Study: Jury Decision Making in a Criminal Trial

Research Personnel: This study is being conducted by Master's student Laura McManus from the Department of Psychology (lauramcmanus@cmail.carleton.ca), under the supervision of Dr. Evelyn Maeder from the Institute of Criminology and Criminal Justice/Department of Psychology at Carleton University (evelyn_maeder@carleton.ca).

Concerns: Should you have any ethical concerns regarding this study, please contact Dr. Shelley Brown (Chair, Carleton University Ethics Committee for Psychological Research, Shelley_Brown@carleton.ca, 613-520-2600 ext. 1505). For other concerns, please contact Dr. Anne Bowker (Chair, Department of Psychology, psychchair@carleton.ca, 613-520-2600 ext. 8218)

Purpose: This is a study to evaluate how people process trial information.

Task Requirements: You have been asked to participate in a study concerning how people process trial information. During this study you are asked to read a trial transcript involving a criminal charge. You are asked to read the entire transcript and then determine a verdict as well as answer several other opinion-related questions. This study will take you approximately 20-30 minutes to complete, and you will be awarded $\$ 1.20$ based on completion.

Potential Risk/Discomfort: You will also be asked to answer questions regarding your attitudes about certain sensitive topics and you may become uncomfortable with the nature of the questions. At any time, you may discontinue your involvement in this study. Choosing to withdraw will not affect your standing in the Qualtrics database.

Anonymity/Confidentiality: The data collected in this experiment are strictly confidential. All data are coded such that your name is not associated with the responses you provide. We collect data through the software Qualtrics, which uses servers with multiple layers of security to protect the privacy of the data (e.g., encrypted websites and pass-word protected storage). Please note that Qualtrics is hosted by a server located in the USA. The United States Patriot Act permits U.S. law enforcement officials, for the purpose of an anti-terrorism investigation, to seek a court order that allows access to the personal records of any person without that person's knowledge. In view of this we cannot absolutely guarantee the full confidentiality and anonymity of your data. With your consent to participate in this study you acknowledge this. This database will be kept for two years, and then destroyed. The information in this database cannot be matched to 
your responses. All the information you provide will be strictly confidential. These data will only be used for research at Carleton University.

Right to withdraw data: In addition, you may refrain from answering any questions on the questionnaire if you are uncomfortable or otherwise do not want to. At any point in the study, you may withdraw and this will not affect your status with Qualtrics. At the end of the study, you will be asked if you would like to withdraw your data from the study and will have the option of doing so immediately if you should so wish.

This study has been approved by the Carleton University Ethics Committee for Psychological Research (\#13-185).

I have read the above form and understand the conditions of my participation. My participation in this study is voluntary, and I understand that if at any time I wish to leave the experiment, I may do so without having to give an explanation and with no penalty whatsoever. Furthermore, I am also aware that the data gathered in this study are confidential and anonymous with respect to my personal identity. By checking this box, I'm indicating that I agree to participate in this study.

I have read the above form and understand the conditions of my participation. My participation in this study is voluntary, and I understand that if at any time I wish to leave the experiment, I may do so without having to give an explanation and with no penalty whatsoever. Furthermore, I am also aware that the data gathered in this study are confidential and anonymous with respect to my personal identity. By checking this box, I'm indicating that I do not agree to participate in this study. 


\section{Appendix I \\ Juror Eligibility}

1. How old are you? (Please specify in years)

2. Are you a Canadian citizen?

Yes

No

3. Are you able to read, write, and understand the English language?

Yes

No

4. Have you ever been convicted of an indictable offence that you have not received a formal pardon for?

Yes

No 


\section{Appendix J \\ Debriefing Form}

\section{What are we trying to learn in this research and how was this study designed?}

The purpose of this study is to understand how a defendant's race and racially charged media affects jurors' decisions. The article you reviewed was an actual commentary from the Canadian Press that was systematically altered to reflect racial content that was general or specific to the defendant's race. On the contrary, the trial transcript that you read was not an actual trial, but was rather fabricated for this line of research. None of the individuals in the photographs which you viewed were actually involved in such a case, to our knowledge. We systematically changed both the defendant's race (White, Black, Aboriginal-Canadian) and article (race specific, general race, race neutral). We are interested in seeing how defendant race and racially charged media affect juror verdicts and sentencing choices.

\section{Why was the use of deception necessary?}

Deception occurs when information is intentionally omitted or when misinformation is intentionally delivered. In our study, we were not able to inform you of the specific purpose of the study, nor of the specific nature of the questions which we asked you to answer prior to your completion of the study. The effect of race on juror decision-making may be an unconscious one and is an effect created through societal norms and values. Informing participants about the true purpose of our study would inevitably change how they viewed the defendant on the basis of race. Deception was also employed in order to avoid an effect of social desirability, which is a phenomenon where individuals modify their answers to fit with what they perceive to be socially acceptable. Please be aware that in the event that you are uncomfortable you may withdraw without penalty.

\section{What are our hypotheses and predictions?}

We predict that defendant race will affect trial decisions based on jurors' attitudes. Specifically, higher levels of racial bias will be associated with higher levels of guilt certainty and less favorable impressions of the Black and Aboriginal-Canadian defendant. However, we predict that this effect may be diminished in trials where participants have read a racially charged article, given that highlighting racial issues may lead participants to become aware of their potential biases and thus correct for them (Sommers \& Ellsworth, 2000).

In our view, it is important to identify racial stereotypes in general, and specifically in a legal context so that we can identify how these stereotypes might affect specific racial groups, and potentially work to reduce these stereotypes.

\section{Where can I learn more?}

- Mitchell, T. L., Haw, R. M., Pfeifer, J., \& Meissner, C. A. (2005). Racial bias in juror decision-making: A meta-analytic review of defendant treatment. Law and Human Behavior, 29, 621-637. 
- Sommers, S. R., \& Ellsworth, P. C. (2000). Race in the courtroom: Perceptions of guilt and dispositional attributions. Personality and Social Psychology Bulletin, 26, 1369-1379.

\section{What if I have questions later?}

If you have any remaining questions or concerns, please feel free to contact Laura McManus (Department of Psychology, at lauramcmanus@cmail.carleton.ca), or Dr. Evelyn Maeder (Institute of Criminology and Criminal Justice, at 613-520-2600 ext. 2421 evelyn_maeder@carleton.ca). Should you have any ethical concerns, please contact Dr. Shelley Brown (Chair, Carleton University Ethics Committee for Psychological Research, Department of Psychology, Carleton University, at 613-520-2600 ext. 1505), Dr. Anne Bowker (Chair of Department of Psychology, Carleton University, at 613-5202600 ext. 8218).

This study has been approved by the Carleton University Ethics Committee for Psychological Research (\#13-185).

\section{Is there anything I can do if I found this experiment emotionally draining?}

Yes. It is natural to feel uncomfortable when considering the impact of racial stereotypes, particularly when your race is targeted. If this experiment has caused you any distress that persists for more than 5 minutes, please contact The Mental Health Helpline 1-800273-8255 or visit http://www.mentalhealthhelpline.ca. These resources will provide you the opportunity to discuss your feelings and experiences regarding racial stereotyping. 


\section{Appendix K \\ Consent-to-keep-data Form}

The purpose of a consent-to-keep-data form is to make sure that you are able to make an informed decision regarding whether or not you would like your data included in this study. We have included this form after explaining the true purpose of our study and the reasons for which deception was necessary. This form is meant to give you an opportunity to withdraw your data from the study, now that you are aware of its purpose. In the event that you wish to withdraw your data, it will be destroyed.

By answering this form, you indicate that you understand that you were not informed of the true purpose of this study prior to completing your participation in the study, and that you understand the reasons regarding the necessity of the use of deception in this study.

Please indicate whether you do / do not continue to consent to the use of your data.

I consent to the use of my data

I do not consent to the use of my data

Thank you for your participation in this study! 